\title{
INTERDISCIPLINARIEDAD HACIA UNA ECOLOGÍA COMPLEJA DE LAS IDEAS
}

\section{Interdisciplinarity Towards a complex ecology of ideas}

\author{
DES GASPER 1 \\ ${ }^{1}$ International Institute of Social Studies, The Hague, A graduate school within \\ Erasmus University Rotterdam, The Netherlands
}

E-mail: gasper@iss.nl

Recibido: 29 de Octubre de 2011

Aceptado: 23 de Enero de 2012

Artículo de revisión

Resumen

Muchas de las discusiones acerca de la interdisciplinariedad muestran uno o más de los siguientes defectos: 1. Confusión conceptual - falta de un conjunto refinado y consistente de términos para analizar la interdisciplinariedad y sus variantes; 2. Utopianismo - falta de realismo acerca de las restricciones que existen en la organización social de las ciencias; 3. Monismo -respaldo a un sólo modelo organizacional simple y no a un modelo heterogéneo complejo con múltiples nichos, nodos y formas de interacción. El artículo ofrece un enfoque de la interdisciplinariedad más refinado, realista y pluralista. Lo hace con referencia especial a los estudios del desarrollo, cuyo interés en el cambio a largo plazo y la combinación común de enfoque de casos y orientación de políticas, los guían fuertemente hacia la interdisciplinariedad y a problemas que surgen debido a lo anterior por la concepción frecuente de la economía como una disciplina de por sí con un status superior. El artículo conceptualiza un rango de tipos de interdisciplinariedad, más allá de la clásica lista OECD; y se pregunta qué tanto algunos ejemplos - tales como la teoría del capital social y el análisis de derechos - ofrecen "capital social conectivo", caminos accesibles a análisis integrantes eficientes de la clase que se precisa para responder adecuadamente a los desafíos globales.

Palabras claves: Disciplinariedad, Interdisciplinariedad, Multidisciplinariedad, Poli-disciplinariedad, Megadisciplinariedad, Transdisciplinariedad, Ecología, metáforas.

\section{Abstract.}

Much discussion of interdisciplinarity shows one or more of the following defects: 1 . Conceptual confusion lack of a refined and consistent set of terms for analysing interdisciplinarity and its variants; 2. Utopianism lack of realism about constraints in the social organization of science; 3. Monism - advocacy of a single simple organizational model, rather than a complex heterogeneous model with multiple niches, nodes and forms of interaction. The paper offers a more refined, realistic, and pluralistic approach to interdisciplinarity. It does this with special reference to development studies, whose interest in long-run change and common combination of a case-focus and policy-orientation guide it strongly to interdisciplinarity; and to problems raised for this by the frequent conception in economics of itself as a superior status discipline. The paper conceptualizes a range of types of interdisciplinarity, beyond the classic OECD list; and asks how far some exemplars - such as social capital theory and entitlements analysis-offer 'bridging capital', accessible paths to effective integrative analyses of the types that are needed to respond adequately to global challenges.

Keywords: Disciplinarity, Interdisciplinarity, Multidisciplinarity, Poly-disciplinarity, Mega-disciplinarity, Transdisciplinarity, Ecology, Methaphors. 


\section{INTRODUCCIÓN}

La necesidad de evitar un marco disciplinario fijo, por no hablar de único, en la concepción y consideración de casos específicos, adquiere especial importancia en campos como los estudios del desarrollo y la ecología humana, con el fin de tratar casos en su propio derecho, su propia complejidad, no por imposición desde una metrópoli de modelos universales sobre simplificados. Los estudios del desarrollo, por ejemplo, han usado la interdisciplinariedad como legitimización de su espacio organizacional distintivo. Mantener esa pretensión a la legitimidad no es ni sencillo ni puede siempre lograrse, más sin embargo el espacio organizacional depende en últimas de ello. El presente artículo examina justificaciones y problemas relacionados con la interdisciplinariedad, al igual que variedades de ella, a fin de proporcionar una perspectiva realista sobre sus prospectos y papeles.

La inter-disciplinariedad trata con la interacción entre disciplinas, y algunas veces más allá de ellas, lo que cubre muchos patrones de actividad y resultados que necesitan ser distinguidos y no soslayados de modo oportunista en la discusión. La falta de una terminología consistente y perspicaz puede ser fatal cuando entran en juego intereses y emociones fuertes. El término se usa de manera típica con descuido, incluso por muchos autores individuales, para significar diferentes cosas, tales como: la multidisciplinariedad (MD), que hace referencia al conocimiento y/o al uso de más de una disciplina; la poli-disciplinariedad, que es el dominio de más de una disciplina por una persona; la mega-disciplinariedad, que es la síntesis de disciplinas en un mega-marco; o la transdisciplinariedad, que trasciende los marcos estandarizados.

Algunos autores tratan la interdisciplinariedad (ID) como un supuestamente inalcanzable ideal de mega o polidisciplinariedad, por ejemplo Johnson (1986), Dogan \& Pahre (1990) y Easton (1991), o como un sinónimo de In-Disciplina, aunque esta imagen de programas de estudio de ID está lejos de su mejor práctica. ${ }^{1}$ La interdisciplinariedad debe juzgarse por sus frutos. Algunos estudios reportan la mayor fecundidad frecuente de la "investigación a través de fronteras", o trabajo en una intersección de perspectivas, por ejemplo Gerstein et al. (1988) y Dogan (2000). En posible contraste, el prominente economista del desarrollo de Harvard y especialista en China, Dwight Perkins, advierte que: "Hay una larga, larga historia de fracaso en el trabajo

\footnotetext{
${ }^{1}$ Véase, por ejemplo, el sitio web de la Association for Integrative Studies. 'ID' usado como sustantivo en este artículo puede hacer referencia tanto a "inter-disciplinariedad" como la "interdisciplinariedad", dependiendo del contexto; y de modo similar la "MD". Lo mismo vale para sus usos como adjetivos.
}

multi-diciplinario" citado por Norbye (1992). Él sostiene que la multi-disciplinariedad (MD) se requiere para muchos problemas de políticas, pero quizás no es adecuada para la construcción de teorías.

La segunda sección comenzará con las afirmaciones similares de Glenn Johnson acerca de la necesidad de reconocer tres modos de investigación social: la investigación disciplinaria tradicional que se guía por métodos y teorías; la investigación orientada a casos, guiada por la presión de entender una situación específica y no sólo aspectos seleccionados; y la investigación orientada hacia problemas prácticos de políticas, guiada por la presión de responder a la percepción de un problema de vida.

En los últimos dos modos, Johnson ve fuertes razones para el trabajo de la ID y la MD. Nosotros iremos entonces más allá, para ver el caso de la ID también en mucho trabajo explicativo. No se puede en general justificar una suposición de aspectos "sociales", "políticos", "económicos" "físicos" separados, que interactúan sólo ocasionalmente.

En el caso del medio ambiente y el desarrollo por ejemplo, las percepciones más profundas y la mayor adecuación del trabajo inter-disciplinario aparecen con claridad, a aquellos con el compromiso y la habilidad para leerlo. Sin embargo, la decisión acerca de cuáles formas y niveles de interacción tienen mejor relación costo-beneficio requiere un análisis cuidadoso. El entendimiento de la ID requiere entender la disciplinariedad, y considerar cómo trabaja la ciencia como una empresa social, sicológica y organizacional.

La tercera sección discute la naturaleza de las disciplinas y las restricciones y requerimientos de la ID. La corriente principal de la economía recibe atención especial en razón a su involucramiento problemático en la ID, de hecho su tendencia a hacerle resistencia (Lipton 1970), y el significado de esta tensión dentro de los estudios del desarrollo en particular.

La cuarta sección analiza posibilidades de promoción e implementación de la ID. Necesitamos en particular un lenguaje mejor para discutir y facilitar varios tipos de ID. Un objetivo inmediato del artículo es proporcionar una imagen más clara de los tipos de nichos, funciones y restricciones relevantes.

Una imagen vieja y todavía útil es la de "construir y usar puentes", que se basa en la "metáfora de la isla" señalada por Berge \& Powell (1997) y es más optimista que la "metáfora del cactus" para las disciplinas. Cactus del desierto, archipiélagos conectados por puentes, poli- y multidisciplinariedad (uso conjunto de múltiples disciplinas separadas) están lejos de ser la únicas posibilidades reales. 
Klein (1996), Salter \& Hearn (1996), y Frodeman et al. (2010) ilustran muchas otras.

La misma metáfora de la isla implica la existencia de espacios entre las islas que no están cubiertos por las disciplinas existentes, y el mejor intento por fijar la atención en ellos no sería siempre mediante la construcción de nuevas islas sino que a veces se debiera pensar en otros arreglos, por ejemplo “zonas de comercio"; véase Jasanoff (2010) y Miller (2010).

Deberíamos reconocer y promover un "ecosistema" intelectual complejo con múltiples tipos de formas de vida y sub-sistemas legítimos, de interacciones de ideas, investigadores y usuarios.

La quinta sección analiza varios estilos de relaciones a través de las fronteras - sean de tipo cooperativo o no, sean marginales o centrales. Se especifican tipos de interdisciplinariedad y algunas de sus respectivas limitaciones y atractivos. La clasificación OECD/CERI de la década de 1970 continúa siendo un buen punto de partida y resulta muy superior al intento por discutir una gran cantidad de variantes con sólo uno o dos términos; pero necesita ser refinada.

Necesitamos ideas teóricas y empíricamente fundamentadas sobre factores que favorezcan la ID, la construcción de puentes y el crecimiento fructífero del ecosistema intelectual. Algunos pasos sugeridos ya han sido implementados: la distinción entre modos de investigación; la clarificación terminológica; el entendimiento de disciplinas como islas ligadas a la cultura, para tratar con las cuales los "nativos" requieren de habilidades especiales; la promoción de "intereses comunes" valores compartidos, incentivos, presiones o experiencias; y la construcción y el uso de marcos intelectuales mutuamente accesibles.

La sección 6 se enfoca en tipos de "capital social conectivo", marcos intelectuales para promover la interacción y la profundización mutua. Con referencia a la necesidad especial en los estudios del desarrollo de involucrar y mantener la economía en plena conversación con otras disciplinas, se pregunta qué hace que algunos puentes parezcan más accesibles y sin embargo no muy crudos, que atraigan en lugar de que repelan.

\section{LOS FUNDAMENTOS DE LA I.D. Y UN PRIMER MAPEO DEL ECO-SISTEMA}

¿Cuál es la base de la interdisciplinariedad?

Consideremos primero un punto de vista que liga la ID a la investigación enfocada en casos o en políticas. Al menos para tales propósitos, los leales a una disciplina deben trabajar con otras disciplinas.

Vemos sin embargo que el fundamento de esta conexión justifica también mucha ID en la investigación general orientada a explicar. Enriquecemos entonces la imagen, usando la perspectiva histórica de Wallerstein sobre cómo las divisiones disciplinarias en la ciencia social emergen y continúan evolucionando. Las divisiones convencionales continúan dominando pero han sido modificadas significativamente en la periferia durante las dos pasadas generaciones. Examinamos cómo estos fundamentos de la ID se reflejan en los estudios del desarrollo, uno de los campos periféricos que emergió después de 1945, y algunos de los desafíos que enfrenta para sostener sus aspiraciones a la ID.

Propósitos de la investigación: orientada a la teoría, orientada a casos particulares, orientada a las políticas.

Si se desea entender una persona particular, un grupo, una localidad, o un país, se debe considerar una variedad de aspectos y cómo ellos se interrelacionan, o sea debe convertirse en "interdisciplinario". Si se quiere estudiar el impacto de las crisis financieras en México, o Gran Bretaña, o los ajustes estructurales económicos en Yugoslavia o Rwanda, no se puede con sensatez ignorar los impactos políticos, además de sus repercusiones en la vida económica.

Al estudiar cualquier país, como país o aun como "economía", no se puede ignorar la posibilidad de que el poder económico se convierta en poder político, a través de fondos para campañas, favores, sobornos, control de los medios, adquisición de un mayor conocimiento, y otros medios, lo que a su vez afectará los sistemas económicos. O si se estudia el impacto de la educación en la India no se puede con sensatez ignorar los impactos culturales, tales como, que con frecuencia cada vez mayor, ninguna persona con un cierto nivel de escolaridad en lo sucesivo desempeñará trabajos manuales pesados, o aun cualquier trabajo manual, que es un hecho económico importante.

Consideraciones similares se aplican cuando consideramos la ID en la investigación orientada a políticas. A menudo se trata de un caso especial de investigación enfocada a casos particulares, aunque otro tipo de trabajo con políticas aspira a generalizaciones más ampliamente aplicables. La complejidad de casos relacionados con políticas excede a menudo el alcance del conocimiento logrado por medio de las disciplinas, aun cuando provenga de varias disciplinas.

Mucho del trabajo de la ID surge en respuesta a situaciones con situaciones problemáticas de vida donde no podemos esperar un eventual conocimiento disciplinar. Tal trabajo 
puede algunas veces no ser organizado o convencionalmente gratificante desde el punto de vista científico, pero requiere de habilidades sofisticadas de juicio, selección y síntesis (Brewer 1999, Rein \& Schőn 1994).

Glenn Johnson, un distinguido economista agrícola y del desarrollo, fue también un metodólogo inusualmente reflexivo, véase Johnson \& Zerby (1973). Su libro Research
Methodology for Economists - Philosophy and Practice distingue tres modos de investigación - positiva, evaluativa y prescriptiva - y tres posibles propósitos: generar teorías, obtener iluminación en casos, y apoyar la acción (los dos últimos a menudo coexisten). A partir de lo anterior yo derivo la (Tabla 1).

Tabla 1. Tipos de investigación, clasificados por propósito y modo, basado en Johnson (1986). La elucidación de los modos y el contenido ilustrativo en las cajas son míos; las etiquetas "disciplinares" y las de los "temas" son de Johnson. ${ }^{2}$

\section{PROPÓSITOS DE LA INVESTIGACIÓN}

\begin{tabular}{|c|c|c|c|c|}
\hline 尺 & & $\begin{array}{l}\text { 'DISCIPLINAR' (en } \\
\text { el sentido de tener } \\
\text { una orientación } \\
\text { teórica general) }\end{array}$ & $\begin{array}{c}T E M A S^{\prime} \\
\text { (descripción y/o explicación de un } \\
\text { asunto/ situación/ caso/ situación) } \\
\text { específico }\end{array}$ & $\begin{array}{c}\text { RESOLUCIÓN DE } \\
\text { PROBLEMAS } \\
\text { /RESPUESTA PRÁCTICAS }\end{array}$ \\
\hline 至 & $\begin{array}{c}\text { POSITIVO } \\
\text { (descripción E } \\
\text { explicación más } \\
\text { neutrales) }\end{array}$ & $\begin{array}{l}\text { Por ejemplo: la } \\
\text { economía central; } \\
\text { o las sociologías de } \\
\text { la economía, de la } \\
\text { ley, de la ética. }\end{array}$ & $\begin{array}{l}\text { Por ejemplo: estudios de área, mucho } \\
\text { de la historia, algo de biografías. }\end{array}$ & $\begin{array}{c}\text { Como un componente que } \\
\text { contribuye al trabajo } \\
\text { prescriptivo; incluso en la } \\
\text { ausencia de una teoría genera } \\
\text { madura. }\end{array}$ \\
\hline 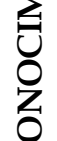 & EVALUATIVO & $\begin{array}{l}\text { Por ejemplo, ética: } \\
\text { teorías del bien. }\end{array}$ & $\begin{array}{l}\text { Por ejemplo: mucho de la historia y } \\
\text { biografía; revisión de estrategia. }\end{array}$ & $\begin{array}{l}\text { Por ejemplo: evaluación de } \\
\text { programas; y como base del } \\
\text { trabajo prescriptivo. }\end{array}$ \\
\hline $\begin{array}{l}\text { ñ } \\
\text { D } \\
0 \\
\vdots\end{array}$ & PRESCRIPTIVO & $\begin{array}{l}\text { Por ejemplo; ética: } \\
\text { teorías de lo } \\
\text { correcto; y algo de } \\
\text { teoría general de lo } \\
\text { legal. }\end{array}$ & $\begin{array}{l}\text { En la definición de Johnson, el trabajo } \\
\text { por "temas", "rara vez es } \\
\text { prescriptivo"; pero de hecho la } \\
\text { orientación a casos y la orientación a } \\
\text { solución de problemas pueden } \\
\text { coexistir. }\end{array}$ & $\begin{array}{l}\text { Trabajo en problemas } \\
\text { prescriptivos: por ejemplo, } \\
\text { análisis de políticas } \\
\text { prescriptivas, trabajo en casos } \\
\text { legales. }\end{array}$ \\
\hline
\end{tabular}

La clasificación de Johnson proporciona un valioso punto de partida, pero no todas las disciplinas están centradas en la teoría. Podemos identificar disciplinas enfocadas en "temas" como la historia o los estudios Chinos, y disciplinas enfocadas en la solución de problemas como la ingeniería y el derecho.

Varios campos orientados hacia la práctica, como la ingeniería y el derecho, han tratado de ser simultáneamente una profesión y una disciplina académica, pero no todas tienen tanto éxito. La administración pública y la planeación urbana y regional, para tomar dos ejemplos importantes, son quizás mejor vistas como "campos interdisciplinarios" (Gasper 1990, 2000a)2; lo mismo sucede con los estudios del

\footnotetext{
${ }^{2}$ El término es usado en la misma forma que lo hacen Klein (1996)
} y Salter \& Hearn (1996). desarrollo. La administración pública trabaja en la encrucijada de varias disciplinas y un conjunto de demandas prácticas. Comparada con la administración general requiere un involucramiento mayor del derecho, la historia y la economía, y no puede ser simplemente una sub-disciplina de la administración o la ciencia política. Mientras que las disciplinas pueden alcanzar un alto grado de enclaustramiento alrededor de conceptos, métodos y preguntas auto-definidos, y dejar de lado tópicos no convenientes a esta matriz disciplinar, una empresa vasalla orientada hacia la práctica como la administración pública no debería nunca adoptar tal priorización del orden por encima de la utilidad. Tiene que acercarse a varios tipos de entendimientos para manejar varios tipos de asuntos reales urgentes e inter-conectados; relaciona material de diferentes campos sin unificarlos (Gasper 2000a). Nunca ha sido, y 
nunca debería serlo, una disciplina unificada: “La integración no resulta tanto en un cuerpo coherente de conocimiento sino que está inevitablemente marcado por definiciones y concepciones en competencia. Esto ayuda a explicar el fracaso, aun mayor que para la administración general, de convertir la administración pública en una profesión cerrada con condiciones de acceso obligatorias bien definidas. El consenso total acerca de la identidad y la ubicación es de hecho innecesario: podemos ganar por medio de la competencia entre ideas, y hay muchas bases intelectuales legítimas, de varias disciplinas y escuelas dentro de ellas, de modo que hay lugar en la administración pública para diversas especializaciones y nichos (Gasper 2000a).

Buscando persuadir del valor de la ID a una audiencia disciplinar de economistas, Johnson la presenta sólo para la investigación enfocada en casos y en la solución práctica de problemas. ${ }^{1}$ Es cierto que construir una teoría conjunta es usualmente más difícil que lograr la cooperación en los casos relacionados con políticas, donde se debe conectar creativamente a un tiempo, lugar o caso particular, herramientas generales relevantes, como en la práctica de un arte, en contraste con una ciencia donde se aspira a capturar dentro de una formulación general toda o la mayor variación posible. Pero también para los propósitos puramente explicativos la defensa de la ID a menudo es válida en vista de los límites del punto de vista de una sola disciplina y la necesidad de una perspectiva más amplia. Si no se pueden analizar con sensatez los resultados del ajuste estructural económico en Yugoslavia o Rwanda cuando se ignoran sus (desastrosas) repercusiones políticas - y por lo que apunta a un proceso de lucha continua por la confrontación de enfoques divergentes a fin de entender mejor algún aspecto de (lo que constituye) la realidad administrativa... la integración no solo resulta en construcción de puentes entre teorías sino que apunta también a las diferencias insalvables" entre sus perspectivas subyacentes (Rutgers 1998). Un campo interdisciplinario tanto económico (Woodward 1995, Uvin 1999), ni la educación en la India cuando se ignoran los impactos económicos indirectos de la aversión masiva al trabajo doméstico, ni los resultados del liberalismo económico cuando se ignoran las repercusiones de la concentración masiva de riqueza sobre la política y los conflictos, no pueden ignorarse estas dimensiones en una teoría adecuada de ajuste económico o desarrollo económico.

Gunnar Myrdal argumentó con fuerza lo anterior en las

\footnotetext{
${ }^{1}$ Krohn (2010) de igual manera vincula abrumadoramente la ID con trabajos de casos; sin embargo muchos otros capítulos en el mismo Handbook muestran otros tipos importantes de ID - ver, por ejemplo, los capítulos 7, 27, 30, especialmente Calhoun \& Rhoten (2010).
}

décadas de 1960 y 1970 , véase por ejemplo Myrdal (1975). Su rival Hayek (1956) advirtió de igual modo que "el economista que es sólo un economista puede convertirse en una molestia, si es que no en un peligro real."

\section{Disciplinariedad e inter-disciplinariedad en una perspectiva histórica}

La concepción de Johnson toma demasiado por sentado las disciplinas ahora tradicionales. Immanuel Wallerstein muestra como ellas no son eternas, sino que emergen - y no de manera idéntica en todos los países - y van evolucionando. En la (Tabla 2) se resumen los análisis del Informe de la Comisión Gulbenkian para la Reestructuración de las Ciencias Sociales que Wallerstein presidió (Wallerstein 1996). Se destacan cuatro divisiones convencionales y bien establecidas en el terreno de los estudios sociales:

1. con orientación pasado-versus presente;

2. si el foco es en supuestas sociedades "modernas" o "no modernas", como se ven desde Europa (o sea: acerca de Europa y sus vástagos y supuestos precursores, o acerca del resto del mundo);

3. nomotética (en busca de leyes generales) versus idiográfica (en busca de conocimiento de casos únicos); y

4. economía versus ciencia política versus sociologia: los tres principales destilados nomotéticos, orientados al presente y a lo "moderno" que surgieron como fracciones de estudios sociales más integrados a finales del siglo XIX y comienzos del siglo XX.

Wallerstein (1996) hace énfasis en el carácter condicional y cambiante de las fronteras disciplinares. La ciencia ha sido impulsada en parte por el poder y las recompensas, y por cualquier clase de datos creados y disponibles, y por lo tanto directa o indirectamente por las necesidades de los estados y los tipos de estudio que han alentado. 'Casi todos los científicos sociales asumen que las fronteras políticas fijan los parámetros espaciales de otras interacciones claves - la sociedad de los sociólogos, la economía nacional de los macroeconomistas, la nación de los historiadores... la ciencia social ha sido con mucho una criatura, sino una creación, de los estados, tomando sus fronteras como contenedores sociales' (Wallerstein 1996). Con la expansión de las 'tres principales ciencias sociales nomotéticas en el mundo no occidental, estas áreas se volvieron también sujeto de análisis centrados en el estado. El concepto clave posterior a 1945 del "desarrollo" se refería primero y principalmente al desarrollo de cada estado, tomado como una entidad individual. Hoy en día, el pensamiento del 'Desarrollo Humano' y la Economía Política Internacional han comenzado a apartarse de esto. 
La Comisión Gulbenkian destacó la eflorescencia del trabajo desde la década de 1950 que de una u otra manera cruza las líneas estándar, a pesar de que duda de que esto sea suficiente. Avanzando sobre el trabajo de Jean Piaget, Dogan \& Pahre (1990) consideran esta tendencia en detalle, bajo el nombre de hibridación. Ellos ven un ciclo sin fin conducente a áreas de estudio cada vez más especializadas pero con cada vez más fertilización cruzada. Los campos científicos muestran continuamente creciente especialización, estrechamiento de enfoque, y subdivisión: creación de subdisciplinas. Esto produce un trabajo más profundo, pero deja también huecos y progresivamente encuentra rendimientos decrecientes. Los innovadores identifican entonces mayores rendimientos de la hibridación a traves de las fronteras con otra parte especializada, a menudo de otra disciplina. Un nuevo sub-campo, mas especializado, emerge; y el ciclo entonces se repite, una y otra vez. Dogan \& Pahre (1990) abogan por el reconocimiento del ciclo especialización-hibridación como deseable e inevitable. La interacción entre especializaciones es un aspecto crucial, enriquecedor, dinamizador de la ciencia, ver también Klein (1996), Salter \& Hearn (1996). Aunque el tipo de "trabajo de servicio" de la ID por el que aboga Johnson es visto a menudo como parasitario de las disciplinas fuertes, las disciplinas de hecho dependen ellas mismas, de la fertilización cruzada a traves del trabajo de la ID (Hansson 1999).

Tabla 2. Anatomía y genealogía de Wallerstein (1996) de los estudios sociales modernos.

\begin{tabular}{|c|c|c|}
\hline & NOMOTÉTICO & IDIOGRÁFICO \\
\hline $\begin{array}{l}\text { CON ORIENTACIÓN } \\
\text { AL PRESENTE } \\
\text { I. 'Sociedades } \\
\text { modernas' }\end{array}$ & $\begin{array}{l}\text { - “La Triada”, resultado de la evolución del } \\
\text { pensamiento social europeo del siglo 19: } \\
\text { 1. Economía: negocios y mercados } \\
\text { 2. Ciencia Política: política } \\
\text { 3. Sociología: 'sociedad' }\end{array}$ & $\begin{array}{c}\text { - Estudios culturales \& algo de la antropología } \\
\text { del nuevo estilo (estas de algún modo han } \\
\text { reducido la vieja división ciencias sociales v. } \\
\text { humanidades) }\end{array}$ \\
\hline $\begin{array}{l}\text { II. 'Sociedades pre- } \\
\text { modernas' }\end{array}$ & $\begin{array}{l}\text { - Expansiones posteriores a } 1945 \text { de la Triada para } \\
\text { discutir el mundo no-europeo }\end{array}$ & - Algo de la antropología del viejo estilo/etnografía \\
\hline $\begin{array}{c}\text { Sub-campos } \\
\text { emergentes } \\
\text { transversales, a través } \\
\text { de la división pasado- } \\
\text { presente, etc. }\end{array}$ & \multicolumn{2}{|c|}{$\begin{array}{l}\text { La proliferación posterior a } 1945 \text { de sub-campos superpuestos (por ejemplo: historia económica } \\
\text { cuantitativa) que cruzan una o más de las cuatro divisiones: } 1 \text {. Con orientación pasado/presente; } \\
\text { 2. Sociedades 'modernas/no-modernas'; 3. nomotético/ideográfico; } 4 \text {. } \\
\text { economía/política/sociología. Mucho del trabajo en tales sub-campos (como la antropología } \\
\text { económica) y campos transversales - estudios de área, estudios del desarrollo, etc. - se ha } \\
\text { preocupado con llegar a un acuerdo con (y ponerles una etiqueta) 'sociedades no-modernas' } \\
\text { particulares, que ya no se dejan en los ghettos del Orientalismo y la etnología. }\end{array}$} \\
\hline CON ORIENTACIÓN & - Historia económica & - 'Historia' \\
\hline $\begin{array}{l}\text { I. 'Sociedades } \\
\text { modernas' } \\
\text { II. 'Sociedades pre- } \\
\text { modernas' }\end{array}$ & $\begin{array}{l}\text { - Expansión posterior a } 1960 \text { del campo de } \\
\text { atención de la historia económica }\end{array}$ & $\begin{array}{l}\text { - 1. 'Clásicos' (acerca de las sociedades que } \\
\text { supuestamente generaron la modernidad: antiguas } \\
\text { Grecia y Roma) } \\
\text { - 2. Orientalismos = estudio de las otras sociedades } \\
\text { pre-modernas; este trabajo ha sido actualmente en } \\
\text { parte absorbido por los estudios de área y por campos } \\
\text { antes abrumadoramente orientados al presente }\end{array}$ \\
\hline
\end{tabular}

A Wallerstein (1996), en contraste, les preocupa 'que el reconocimiento de la "interdisciplinariedad" haya servido tanto para salvaguardar la legitimidad de las disciplinas existentes como para superar la menguante lógica de su individualidad. La Comisión Gulbenkian, entre otros, instó por una reconstrucción más radical para superar lo que percibe como confusión intelectual'. A pesar de que los campos híbridos pueden florecer cuando los recursos son abundantes, cuando la escasez aprieta las viejas disciplinas establecidas a menudo se movilizan para suprimir los nuevos competidores, por lo que no puede permitirse el lujo de evitar o retrasar el asunto de cómo reconstruir las disciplinas de la ciencia social convencional (Wallerstein 1996). Sin embargo, advierte la Comisión, las viejas disciplinas poseen 
de la ciencia social convencional (Wallerstein 1996). Sin embargo, advierte la Comisión, las viejas disciplinas poseen fuerza organizacional y grandes bases de poder (lo que se une a su dominio de la enseñanza básica y al poder de conceder títulos de Ph. D.) y sostiene que ellas se han profundizado y se han hecho más sutiles desde la década de 1950 cuando se sintió la necesidad de transcenderlas por medio de los estudios de área y los campos interdisciplinarios.

\section{Los desafíos de los estudios del desarrollo}

Los estudios del desarrollo combinan las razones que da Johnson para la ID: extensa orientación hacia casos y situaciones y orientación hacia políticas, y aquellas dadas por Wallerstein (1996): la necesidad de un punto de vista más amplio en un mundo demasiado complejo e interconectado para ser descrito adecuadamente por las solas disciplinas. Para Hettne (1990), en su Development Theory and the Three Worlds, los estudios del desarrollo son 'un campo interdisciplinario, aplicado y orientado hacia problemas, que analiza el cambio social en un contexto mundial [de disparidades materiales], pero con la debida consideración a la especificidad de diferentes sociedades en términos de historia, ecología, cultura, etc.' (edición 1990); y está de manera típica marcado por preocupaciones normativas y de políticas (Hettne 1995). Aunque la ciencia social del siglo 19 a menudo tenía mucho de esa orientación, si bien eurocéntricamente, fue gradualmente reemplazada en gran parte por un trabajo más compartimentado, estático y abstracto. Mucho del trabajo posterior a la Segunda Guerra Mundial sobre los países de bajos ingresos llevado a cabo en ellos mismos permitió descubrir que se precisa trascender esta corriente principal disciplinar y estática de la ciencia social. Las contribuciones provenían tanto de intelectuales y activistas del Sur quienes encontraban problemática la división del trabajo intelectual establecida para describir la reproducción de las sociedades industriales capitalistas maduras, como de intelectuales y activistas del Norte que trabajaban en la periferia de esas disciplinas. En la fase presente, la abrumadora concentración tercermundista en los estudios del desarrollo ha disminuido al disolverse viejas definiciones acerca de los "Mundos", sin embargo sus enfoques adquieren una aplicación más amplia, que se encuentra necesaria también en el Norte, el Oriente y el Occidente. ${ }^{1}$ Las aplicaciones crudas de la teoría

\footnotetext{
1 En contraste, la posición convencional una generación atrás era que 'los estudios interdisciplinarios (EID) están más fuertemente indicados en países menos desarrollados... puesto que la interacción entre variables que normalmente se tratan en disciplinas separadas es inusualmente fuerte' (Lipton 1970). Supuestamente los EID en absoluto eran indicados para el Norte: primero, porque las divisiones en las ciencias sociales supuestamente 'correspondían a la división de variables en conjuntos que
}

neoliberal y sobre la modernización en el antiguo mundo Comunista, por ejemplo, produjeron el tipo de crisis y reacciones que se vieron antes en el Sur. La desintegración de la antigua Yugoeslavia en la ola de préstamos fáciles en la década de los años setenta, de alza de las tasas de interés en la década de los años ochenta y luego de ajuste estructural crudamente forzado (Woodward 1995), es una ilustración principal de los efectos que se tienen fuera de un campo de visión económico.

La importancia de la teoría del Desarrollo es entonces, de acuerdo con Hettne, la de "una precursora... y catalizadora... que obliga a las ciencias sociales excesivamente especializadas y estáticas a enfocarse en el desarrollo y en el cambio... y a volver a la tradición clásica de una ciencia social histórica unificada" (Hettne 1995), pero ahora con nuevas bases no euro céntricas. Hettne reconoció el predominio desde alrededor de 1980 de la economía neoclásica y el gerencialismo Anglo-Americano. Los estudios el desarrollo no eran sin embargo "una 'disciplina' en desintegración." (Hettne 1995). Alrededor del mundo continuaría el reconocimiento de los requerimientos sociales y del impacto de los mercados y del crecimiento económico, y de sus costos humanos y ecológicos. Los estudios del desarrollo, además, siempre han necesitado ser un campo interdisciplinario intelectualmente, no una disciplina separada, aún más cuando se definen "en términos de problemas y no de países" (Hettne 1995). Tampoco se marchitarán ni se desarrollarán como una disciplina separada. Dadas la preocupaciones y normas internas de las disciplinas, y el hecho de que las necesidades de los países de bajos ingresos son "todavía, y por buenas razones, consideradas como el área central de los problemas del desarrollo" (Hettne 1995), el aconseja que no es el "tiempo para renunciar al espacio organizacional de los estudios del desarrollo. Más bien es importante defenderlo contra la ola creciente de fundamentalismo monodisciplinar..." (Hettne 1995).

Habiendo examinado las justificaciones para los enfoques interdisciplinarios, debemos tener en cuenta las limitaciones establecidas por las razones y las prácticas de la disciplinariedad. A continuación vamos a ver las medidas factibles para seguir adelante.

con seguridad podían ser tratados como "casi independientes" en las culturas para las cuales las especializaciones en una sola disciplina habían sido diseñadas: las de los países ricos'; y segundo, porque se alegaba que los científicos sociales del Norte podían captar la sicología ('confiar con bastante plausibilidad en la empatía', Lipton (1970)) de los agentes del Norte, a diferencia de aquella de los poco estudiados y extraños Sureños, y podían de acuerdo con esto especificar sus modelos. 


\section{LA ORGANIZACIÓN SOCIAL DE LA CIENCIA}

\section{El entendimiento de la disciplinariedad como base para entender e intentar la interdisciplinariedad}

No es por coincidencia que los términos "disciplina" y "discípulo" son cercanos; ni tampoco los dos sentidos de "disciplina" son gemelos por accidente, como Foucault y otros lo han señalado. ${ }^{2}$ Las "disciplinas" consisten en formaciones sociales y así mismo intelectuales. Ellas organizan grupos o redes con miembros disciplinares $\mathrm{y}$ estudiantes-mediante recompensas, castigos y otorgamiento y pérdida de identidad y reconocimientopara crear discípulos. En este sentido son sucesoras de las órdenes sacerdotales. Seducen al mismo tiempo que entrenan, proporcionando a la juventud en una edad impresionable un nido, una comunidad, un estilo y conjunto de hábitos, una inducción gradual en los misterios, y muchas recompensas intelectuales por la emoción y facilidad de manejo de enigmas limitados. Por una variedad de razones, tratadas por teóricos de la ciencia como Kuhn (1970) y Ravetz (1973), un enfoque en profundidad en lugar de en amplitud es a menudo funcional e incluso necesario. En casos donde esto no es así, las disciplinas a menudo desaniman el trabajo exploratorio que cruza las fronteras, con el fin de mantener su territorio.

Sheldon Rotblatt (1999) defiende la disciplinariedad como un sistema que protege la libertad académica contra la dominación política: afirma la existencia de aéreas de conocimiento profundo y organizado que se establecen y se gobiernan únicamente por criterios científicos. Las Universidades son en verdad cunas de la disciplinariedad, dado su papel como un mecanismo para validar la idoneidad de alguien para el empleo como "trabajador intelectual" y para la socialización de la nueva generación de profesores universitarios; dadas también las estructuras que incentivan a los académicos a un juego seguro después y aun durante sus estudios de Ph. D. y para publicar prolíficamente por medio del trabajo detallado (Earl 1983). Al basar las estructuras para la investigación sobre la estructura de la formación, la mayoría de las universidades ponen coto a la investigación. La cooperación en la enseñanza a menudo es aún más limitada. Los académicos a menudo tienen poco o nada que ver con sus colegas en el mismo campus en disciplinas que se suponen hermanas.

La profundidad y la virulencia del chauvinismo disciplinar es de muchos modos sorprendente. Considérense las luchas

\footnotetext{
2 El Diccionario Ingles de Oxford hace derivar el término 'disciplina' del latín discipulus que significa discípulo. Salter \& Hearn (1996) y las fuentes que contiene muestran como esto refleja la historia de las universidades Europeas.
}

frecuentes en los departamentos conjuntos de sociología y antropología: Giri (1998) cita numerosos casos que llevan a una separación, y se puede añadir otros. Aun después de haber establecido sus propios territorios, banderas $\mathrm{y}$ pasaportes, las disciplinas continúan teniendo una relación pobre unas con otras: ignorándose en gran medida y (aun) menospreciándose unas a otras (Salter \& Hearn 1996); y el papel de generalista enlace tiene un estatus típicamente bajo. ¿Por qué es tan común la disciplinariedad cerrada? Entre las razones se pueden incluir la arrogancia científica, el temor a lo desconocido, los primeros títulos en una sola disciplina de las ciencias sociales, la defensa de los presupuestos de los departamentos (de modo que los conflictos con los vecinos más cercanos tienden a ser los más feroces), y la conveniencia deliciosa de la disciplinariedad, como la burocracia, puesto que el mandato es ignorar la mayoría de los aspectos de la situación de los demás.

Debemos notar además tres factores fundamentales. En primer lugar, las disciplinas de las ciencias sociales en algunos aspectos han surgido históricamente como competidoras en lugar de asociadas. En segundo lugar, las disciplinas son culturas, y las culturas divergen; en relación con ese aspecto, ellas proporcionan "hogares" emocionales, fundamentos de identidad. En tercer lugar, el establecimiento de fronteras disciplinares es a menudo sustentado, especialmente en la economía, por una ontología "newtoniana" que declara que el todo es la suma de las partes, las cuales pueden entonces observarse cada una de manera separada.

Primero, las disciplinas y campos de las ciencias sociales no han crecido como asociados. Foster-Carter (1998) arguye que las ciencias sociales son competidoras por el dominio, y no una cadena de subconjuntos emergentes como físicaquímica-biología. Representan perspectivas en competencia, algunas de las cuales pueden considerar que cubren todo o contienen a las demás como casos especiales. Se hace poca referencia al papel de las demás.

Segundo, las disciplinas son culturas y los contactos a través de las culturas están plagados de problemas y son exigentes. (Schoenberger 2001). Los diferentes estilos de escritura entre diferentes ciencias sociales, y entre las ciencias naturales y las sociales, forman una barrera (Salter \& Hearn 1996, McNeill 1999, Flottum et al. 2006). La Economía usa el estilo pasado de moda de las viejas historias de detectives: personajes con limitada profundidad interactúan de manera intricada pero estándar. Para algunos lectores esto constituye una delicia, para otros es aburrido a morir. El análisis de estas diferencias de género, incluido las escogencia de las metáforas principales y ejemplos de casos e ilustraciones claves en diferentes disciplinas, podría 
mejorar la comunicación y el conocimiento mutuos (ver, por ejemplo, el trabajo de Apthorpe (1996), Lakoff \& Johnson (2003), McCloskey (1998) y Roe (1998)).

Relacionado con esto, las disciplinas a menudo sirven como base de identidad personal. Consideremos dos situaciones. En la situación A, mi disciplina (mi entrenamiento) tiene mi voto de lealtad (una elección como la del Jesuita versus la del Dominico), constituye mi identidad expresada por un nombre ("yo soy un economista"), una marca de casta, para toda la vida. En la situación B, mi disciplina, afiliación, etiqueta, entrenamiento (originales) son uno de los muchos adjetivos o clausulas descriptivas relevantes de mis antecedentes ("Yo fui entrenado en economía, hace treinta años"). La situación B es más sana, incluso para la interdisciplinariedad, pero la situación A es común, probablemente mucho más común. La ID trabaja más fácilmente cuando la gente actúa como representante no de disciplinas sino de sí misma, de sus experiencias, sus valores y percepciones. Rajni Kothari (citado por Giri 1998) arguye que el paso clave en la ID es la formación de una comunidad de conversadores cada uno de los cuales busca cruzar y quizás trascender los límites convencionales: "Para que la verdadera interdisciplinariedad se desarrolle, es el individuo el que tiene que volverse interdisciplinario, no el grupo". Como las disciplinas pueden volverse fuente de identidad personal, la recomendación de tratar la ID como una fase de seguimiento en la educación, después de que la gente ha estado primero inmersa de manera abrumadora en una disciplina, es problemática. Además, las presiones de la vida profesional después de los estudios de Ph. D. hace menos probable en esa etapa la adquisición de los fundamentos adecuados de otras disciplinas.

Tercero, algunos autores sostienen que la disciplinariedad refleja premisas "newtonianas" dominantes en el pensamiento occidental, aceptadas debido a su inmenso éxito en partes de las ciencias físicas. Siguiendo a Norgaard (1994), las dos primeras premisas son: (i) Atomismo: los sistemas consisten de partes que no cambian, y un sistema es la suma de esas partes; y (ii) Mecanicismo: las relaciones entre las partes no cambian. Dadas tales premisas, un campo de estudio disciplinar puede tomar la mayoría de las cosas como exógenas, constantes, separables, y no afectadas por las restantes cosas que la disciplina considera. Las otras premisas, particularmente influyentes en economía, son las siguientes: (iii) Universalismo: las mismas partes y las mismas interrelaciones aplican en todos los casos, en todas partes. (iv) Objectivismo: las personas que actúan sobre los sistemas no son parte de los sistemas que tratan de entender y sobre los cuales actúan. (v) Monismo: hay una manera correcta de entender un sistema; cualquier pluralidad de maneras de entender se fundirá en un marco mayor; por tanto las diferentes ciencias encajarán sin ninguna dificultad fundamental. Cada una de estas premisas es adecuada en las partes viejas de la física, pero no para sistemas complejos que incluyen a la gente. ${ }^{3}$

Mucho de la economía puede ser aún más ferozmente monista: puede no reconocer otras maneras valiosas de ver un sistema económico o humano (Söderbaum 2000). Así, en contraste con otras ciencias sociales, solo un paradigma, la economía neo-clásica, se enseña hoy en día en muchos de los departamentos de economía, para no hablar mucho sobre otras disciplinas; y el neo-clasicismo busca tener un papel imperial también más allá de la economía (Fine 1999).

\section{El caso especial de la economía dominante}

"Todo aquel que trabaja de manera interdisciplinaria es considerado como un mal economista", reportó el destacado economista ambiental David Pearce en Ravaioli (1995). La discusión sobre la ID en ciencias sociales y en estudios del desarrollo continúa siendo cortésmente vaga, y la discusión de posibles acciones remediales continúa desenfocada, a menos que reconozcamos que las dificultades conciernen aquí de manera más común a los economistas que a los geógrafos humanos o a los antropólogos, o aun a la mayoría de los sociólogos, científicos, políticos y aquellos en estudios culturales. En relación al desarrollo sostenible, los ecologistas están mucho mejor entrenados que la mayoría de los economistas para considerar sistemas que cruzan las fronteras tradicionales de las ciencias. La caja de herramientas de la economía dominante, las formulaciones estandarizadas y constructoras de fronteras dominan a muchos de sus practicantes: "Un error elegante es a menudo preferido a una verdad confusa. La posibilidad de tratamiento teórico es a menudo preferida a la relevancia empírica", se lamenta Richard Lipsey en una importante crítica de un atribulado economista ya mayor con una inmensa experiencia (Lipsey 2001). La economía dominante constituye un problema especial en la interdisciplinariedad dada una combinación de comparativamente pobres "relaciones externas" con otras ciencias, suposiciones a menudo escogidas más por conveniencia que por realismo, y sin embargo fuerte orientación política e influencia.

La Economía tiene problemas mayores en su relación con otras ciencias sociales que los que vemos en otras interfaces de las ciencias sociales. Sus pretensiones de universalidad, la ausencia de límites establecidos para su alcance, producen de manera típica un débil interés por la historia y el cambio cualitativo; y sus logros algunas veces indicen un complejo

\footnotetext{
3 C.T. Kurien (1996) presenta una caracterización similar de un estilo newtoniano adoptado por la economía neo-clásica para estudiar 'la economía'.
} 
de superioridad, que se percibe por ejemplo en algunas de las entrevistas de Swedberg (1990). Los famosos economistas entrevistados por Swedberg sin embargo fueron de modo claro peor recibidos por los sociólogos que su contraparte en sociología por los economistas. Se trata de algo característico: la estructura de citas sugiere que la mayoría de economistas importan poco (Dogan \& Pahre 1990). A pesar de que únicamente una minoría mantiene una visión explicita de la economía como la ciencia social maestra - la ciencia a elegir en general, capaz de absorber los otros campos - la mayoría de los economistas no ve su disciplina como sólo una perspectiva entre otros estudios sociales y humanos con los cuales deben vitalmente interactuar. La educación en otros campos a menudo sitúa temprano el campo en relación con otros (véase por ejemplo el texto clásico de sociología de Bottomore (1971); los textos de economía no lo hacen. ${ }^{4}$ Incluso algunos economistas que practican la ID - el aprendizaje a partir de otras áreas condenan formalmente la nocion, como lo hace Glenn Johnson, quizás porque identifican la ID con la mega- o la trans-disciplinariedad o simplemente con la indisciplina.

La economía parece tener problemas también en otras fronteras. Los científicos naturales pueden encontrar sus supuestos y su metodología extraños (ver Anderson et al. 1988, Waldrop 1993): la común insistencia en que sus presupuestos fundamentales no son reemplazables ni necesitan someterse a prueba, la priorización de la deducción abstracta por sobre la más amplia exploración empírica, y el fracaso hasta fechas recientes en recoger muchos de sus propios datos y conversar con la gente. Sólo recientemente la economía experimental, la economía evolucionista y algunas otras innovaciones han comenzado a modificar esos aspectos, al margen de las disciplina.

Sin embargo ninguna otra ciencia iguala la larga historia, el prestigio, la escala de investigación, la membrecía y la influencia de la economía. En un mundo fundamentado en el dinero y concentrado en el crecimiento, se hace referencia rutinariamente a las sociedades como "economías" y el mundo mismo a menudo se convierte en "la economía

\footnotetext{
4 Por ejemplo: (1) el best seller de Lipsey An Introduction to Positive Economics (edición de 1975) no reconoce la existencia de otras disciplinas en ciencias sociales. Comienza más bien con un largo extracto de William Beveridge sobre la aspiración de la económica a ser como la física. La $8^{\mathrm{a}}$ edicion no menciona en absoluto otras disciplinas (Lipsey \& Chrystal, Positive Economics, 1995). (2) Economics (Edicion de 2002) de Joseph Stiglitz \& John Driffil es igualmente mudo respecto a otras ciencias sociales o a las humanidades. (3) Economics (Edición de 1976) de Samuelson reconoce en unas pocas frases la presencia de campos de estudio limítrofes, que de hecho se superponen - en una sección titulada 'La Reina de las Ciencias Sociales'. La sección, el tema y el reconocimiento desaparecieron en la edición de 1992 (de Samuelson y Nordhaus).
}

mundial". La economía no está inhibida en el asesoramiento políticos por sentimientos de contaminación o degradación; por el contrario, ella confiere al asesoramiento político un alto estatus. Myrdal (1975) examina el contraste que aquí se tiene con otras ciencias sociales; Salter \& Hearn (1996) añaden que también la mayoría de los científicos naturales evitan las exigencias comunes de simplificación radical del discurso político. En tanto que "Los economistas a menudo prefieren teorías que produzcan resultados políticos sin ambigüedad a teorías que no lo permitan, sin que importe lo relativo de su fundamento en la evidencia" (Lipsey 2001). Los economistas no hacen una distinción explícita entre científicos e ingenieros: los economistas se presumen capaces tanto de teorizar como de prescribir. En el debate político un estilo absolutista - proclamación enfática de verdades supuestamente generales - les da a menudo ventajas retóricas (Baker 1998). No contentos con reportar sus hallazgos y dejar a otros el uso de ellos en la argumentación política, los economistas a menudo compiten en escribir un parágrafo o dos sobre "las implicaciones políticas", a partir de premisa y datos extremadamente precarios. Para tomar un ejemplo rutinario de una respetable revista, un estudio sobre la escolaridad en Indonesia encuentra que los graduados de las escuelas privadas ganan más, y toma nota de otros estudios que concluyen que estos graduados también aprenden más y con una mejor relación costobeneficio. (Bedi \& Garg 2000). El estudio inmediatamente "sugiere la necesidad de una mayor participación del sector privado en la educación", a pesar de no haber puesto atención a aspectos como la construcción de nación o la fuga de cerebros o el deseo de trabajar en sectores prioritarios, o las posibilidades de reformar las escuelas públicas. Subyacente a los estrechos marcos de la corriente principal de la economía para el análisis político está un criterio de priorización de la disposición y capacidad para ingresar a la economía mundial, y un estilo de abstracción, derivado de las ciencias físicas, que puede volverse peligroso cuando se aplica a los sistemas sociales o ambientales.

\section{La abstracción y sus peligros}

Un estilo "newtoniano" de teorización ha contribuido a forjar una economía dominante resistente a la ID y parcializada hacia el asesoramiento político categórico y miope. Norgaard (1994), Wallerstein (1996) y en especial Kurien (1996) critican la desatención permanente y no solo temporal de las variables sociopolíticas claves, que son tratadas como constantes en la economía. Norgaard (1994) observa: "Hace quinientos años, con base en la hipótesis de una relación entre la sangre mala y la enfermedad, el sangrado era practicado de manera común. Sabemos ahora que la hipótesis tenía alguna base pero la cura adolecía de una 
visión sistemática del cuerpo. Y llevado a un extremo, como a menudo lo era, la muerte por sangrado es segura" ((Norgaard 1994) las cursivas son mías). Muy cercano a lo anterior ha sido el uso de las predicciones de los modelos económicos altamente abstractos como base para una masiva ingeniería social, como en los programas de estabilización del IMF, las políticas de ajuste estructurales del Banco Mundial, y los planes de transición tipo big-bang del antiguo bloque soviético. La abstracción newtoniana prosperó en la economía no solo por el prestigio de la física newtoniana. Las abstracciones particulares usadas - a partir de relaciones de poder, arreglos de propiedad, el ambiente social, y la justicia - hicieron a la economía neo-clásica una sierva de aquellos en el poder (Kurien 1996), lo que le dio así un apoyo institucional.

Para analizar claramente debemos abstraer: pero debemos hacer abstracción de lo incidental, no de lo esencial, y aún más, no debemos confundir nuestros modelos abstractos con la realidad. La economía dominante a menudo ha hecho sus abstracciones dando prioridad a la conveniencia analítica. Kurien (1996) nos advierte que:

“(...) 'la economía' no es una entidad independiente sino algo que se forja mentalmente para propósitos de investigación (...) no una entidad con fronteras bien definidas, sino siempre fundiéndose con otras esferas sociales (...) permeable en la frontera (...) siempre en un estado de flujo interno ya que es el resultado de la interacción de diversas fuerzas sociales (...) [No existe una frontera precisa para la economía.](...) puesto que los hogares y el estado son parte constituyente de la economía, sus consideraciones "no económicas" se filtrarán en el funcionamiento de la economía (...) [En cambio] las teorías neo-clásicas cortan completamente la economía del resto de los procesos sociales y le confieren una autonomía que no posee (...) Insistiendo en las simetrías, las regularidades y las uniformidades como las propiedades lógicas esenciales de una teoría, la economía neo-clásica ofrece una conceptualización de la economía desprovista de sus aspectos esenciales" (Kurien 1996).

Kurien (1996) concluye que la economía es un mosaico en evolución de unidades con estructura, y agendas heterogéneas y diversos patrones de interacción, que requieren un examen caso por caso y una perspectiva evolutiva. Sin embargo, desarrollar y enseñar un matematizado cuerpo de doctrina ordenado y encerrado en sí mismo que proporciona afirmaciones claras y estandarizados es más fácil que enfrentarse a la realidad.

La economía ha hecho abstracción también del mundo físico, como la sociología y las ciencias políticas, a diferencia de la geografía o la antropología: "la organización disciplinaria del conocimiento en que la economía ha hecho abstracción del mundo físico y se ha enfocado en el intercambio, intercambios de valores y transacciones monetarias (...) dejando [así] de tratar más con el mundo real" (Herman Daly, en Ravaioli 1995) Lo ambiental, lo físico y lo social, se asumen como constantes, aun cuando están siendo saturados con contaminantes. "Lo que la economía piensa que existe en el potencial a largo plazo para el desarrollo es o inconsistente con el conocimiento acumulado en las ciencias naturales o se apoya en una todavía no identificada [y por tanto no probada] fuente de energía" (Norgaard 1994). Si bien el temor de un deterioro ambiental importante ha inducido una respuesta de los economistas y los patrocinadores institucionales, el marco mental de la economía dominante ofrece una resistencia considerable. El medio ambiente no es un tópico obligatorio en el entrenamiento económico. Muchos de los principales economistas entrevistados por Ravaioli no han leído un solo libro sobre economía ecológica o sobre el medio ambiente. El tópico se considera a menudo relativamente trivial tanto desde el punto de vista teórico como práctico: las señales que emiten los precios, mejoradas por alguna internalización de externalidades, transmitirán la información requerida y los incentivos para el cambio cuando ello se haga apropiado, opinaron Milton Friedman, Gary Becker and Frank Hahn, como si los mercados fuesen completos y representasen también a los pobres y a las futuras generaciones. Los intentos por cambiar los estilos de vida y reducir el consumo no tienen "nada que ver con los economistas" declaró Malinvaud (Ravaioli 1995), o no tienen sentido y/o son inaceptables (Friedman; Spaventa); e igualmente lo son también los intentos por cambiar la distribución mundial, a menos y hasta cuando suceda una catástrofe, anunció Hahn.

Al ser presionados los economistas de la economía dominante entrevistados por Ravaioli acudían a la fe: debemos simplemente confiar en la salvación tecnológica, de modo notable en una fuente de masa y energía limpia y barata; o, según algunas respuestas, invocaban la disciplinariedad misma como justificación para no considerar de manera central el ambiente físico. Para Hartje: "La mayoría de las ciencias sociales necesariamente tienen una perspectiva limitada" (Ravaioli 1995); y para Hahn: "La pregunta correcta es aquella para la cual usted puede concebir una respuesta" (Ravaioli 1995). Hahn aplicó el criterio de la investigación disciplinar (Tipo 1 de Johnson) para problemas políticos concretos y urgentes (Tipo 3 de Johnson). Aun así, ¿se debería trabajar en su rincón disciplinario familiar con sus tipos familiares de "respuestas", o interactuar con otros que pudieran ayudar o 
estimular a descubrir los tipos de respuestas y preguntas que no se ha concebido previamente?

\section{SUGERENCIAS QUE SURGEN DE LA INTERDISICIPLINARIEDAD}

\section{Grandes visiones y propuestas viables}

Una vez identificadas las limitaciones de la disciplinariedad, algunos autores hacen llamados audaces a la interdisciplinariedad. Norgaard (1994) construye un argumento persuasivo para abandonar el monismo, que es la premisa de que existe solo una manera correcta de entender un sistema. Los principales participantes en los procesos de aprendizaje y de decisión deben: 1 - hacerse conscientes de sus propios marcos conceptuales, 2 - hacerse conscientes de las ventajas y desventajas de los marcos usados por otros, y 3 - ser tolerantes con el uso de diferentes marcos...por parte de otros' (Norgaard 1994). Una coherencia total en el entendimiento de muchos temas, por ejemplo el cambio climático, es 'inherentemente imposible pues los conocimientos de científicos de disciplinas distintas cubren diferentes variables, diferentes escalas espaciales, y diferentes escalas temporales. Y múltiples patrones de pensamiento incongruentes están siendo usados tales como los modelos mecánicos de los físicos versus los modelos evolucionarios de los biólogos (Norgaard 1994). La integración de estas perspectivas parciales y limitadas debe llevarse a cabo por medio de un tipo de políticas de las ciencias multiculturales y democráticas, quizás tales como las ensayadas por el IPCC:

...el conocimiento debe ser un proceso social donde el entendimiento de disciplinas diferentes debe confluir... Pues los patrones de pensamiento son realmente inconmensurables... Los científicos deberían ser obligados a mantenerse al tanto de los hallazgos importantes en las ciencias que los rodean... y a participar en el intercambio de conocimiento y en la construcción del entendimiento colectivo necesario tanto para evitar los problemas complejos como para trabajar con ellos (Norgaard 1994).

Haciendo uso de la terminología de Martinez-Alier (1999), procedente de Otto Neurath, podemos ensayar una 'orquestación de las ciencias', juntándolas y relacionándolas entre sí, sin esperar ni desear absorberlas en una sola disciplina (vieja o nueva). Y ello incluso para un proceso como el de IPCC, que ha hecho progresos por medio de la interacción intensiva entre disciplinas y el aumento creciente de la confianza y el respeto mutuos:
Cualquier marco dado es mejor entendido o mejor apreciado por algunas personas que por otras, e igualmente resulta en respuestas que son más ventajosas para algunas personas que para otras. Cualquier marco de trabajo que ha sido altamente elaborado con el fin de aumentar su utilidad, solo puede ser entendido por unos pocos que están bien informados de sus detalles técnicos. El uso de un solo marco de trabajo, sin modificación alguna para dar cuenta de las diferencias regionales, facilita el control desde un solo centro de análisis. El uso de un solo marco de trabajo priva de derechos o descalifica entonces a la mayoría, facilita la tiranía de los tecnócratas, y promueve la centralización (Norgaard 1994).

Nuestro análisis ha identificado una serie de obstáculos principales para un entendimiento con una base más amplia. Tenemos que tener en cuenta la atracción gravitacional ejercida por las disciplinas, por buenas o malas razones. La resistencia a la ID proviene no solo del chauvinismo, de la errónea interpretación de ella con los currículos de cafetería o con el diletantismo, o del punto de vista de que es innecesaria. Refleja también la preocupación de que la ID es un fracaso o que es difícil y costosa. Lipton (1970) y Berge \& Powell (1997) advierten por ejemplo que cada nueva disciplina que se añade a un grupo aumenta seriamente los costos de coordinación, por tanto se debe ser muy selectivo. Esta parte del artículo tratará de identificar propuestas manejables y buenos ejemplos. ${ }^{5}$

La Comisión Gulbenkian hace recomendaciones en dos niveles. En primer lugar, una visión revolucionaria: deberíamos reconstruir las ciencias sociales mediante un nuevo plan: por ejemplo, en lugar de hacer una división entre economía, ciencia política y ciencia social, hacer quizás una división entre estudios macro (procesos a gran escala, a largo plazo) y micro (acciones individuales); además todos los científicos sociales y las ciencias sociales debería ser históricas y sociológicas y económicas (Wallerstein 1996). En segundo lugar, presenta sugerencias para el corto plazo (Wallerstein 1996): (1) grupos de investigación mezclados durante un año en centros internacionales, cada uno concentrado en un tema urgente; (2) programas de investigación inter-disciplinarios a término fijo diseñados para probar el potencial de nuevas ideas; (3) todos los profesores deben servir en dos departamentos; (4) todos los estudiantes de investigación deben temer un minor, por

\footnotetext{
${ }^{5}$ Salter \& Hearn (1996) es una fuente valiosa, acerca del trabajo ID en muchos campos en Canadá. Ver también Stokols et al. (2010) en 'the science of team science'.
} 
medio de trabajo de curso o de investigación. Estos arreglos parecen relevantes y factibles. Sin embargo son la excepción. $\mathrm{Ni}$ siguiera las escuelas de estudios del desarrollo practican la mayoría de tales arreglos de modo rutinario. Los nombramientos profesorales y el entrenamiento profesional a menudo son débiles para construir la ID.

Las recomendaciones de Johnson tuvieron como base la revisión de la experiencia con una amplia variedad de modos y propósitos de investigación. Su libro enfatiza la legitimidad y la importancia del trabajo multi-disciplinario, que él entiende no solo como la presencia de varias disciplinas sino como una abierta interacción ID en la investigación enfocada en casos y en la investigación de políticas. Dado sin embargo que tales enfoques son demandantes, complejos y costosos, incluso en términos de gestión, a menudo son mejores las subdivisiones y las especializaciones. Tanto la disciplinariedad como la interdisciplinariedad son legítimas y necesarias, por separado y en grupos de investigación. Son fuertemente complementarias. Kenneth Boulding observa en su prefacio al libro de Johnson que las división intelectual del trabajo logra la economía de la especialización, que como en otros casos de especialización debe ser complementada con el comercio entre especializaciones si se quieren aumentar los beneficios completos. El intercambio no tiene que llevar a un consenso, de hecho el consenso a menudo impide el progreso intelectual; no obstante los puntos de vista en competencia deberían formarse reconociendo al otro, y no en la ignorancia mutua.

Boulding no se pregunta cómo habrá de tener lugar el comercio, si la especialización intelectual conlleva la estrechez de miras y el chavismo mercantilista. Un grupo MD no interactuará automáticamente con otros. Y la ID a menudo ocurre también por fuera de los grupos, por la interacción con personas en otras disciplinas a través de sus escritos. Mucho del mejor trabajo ID sucede dentro de una persona- un Jon Elster, un Albert Hirschman o un Tibor Scitovsky. Como lo vio Kothari, la verdadera ID requiere individuos ID, estén o no en un grupo. Giri (1998, 2002) diagnostica el cambio requerido como de un nido de identidad como profesional del tipo $\mathrm{T}$, a una autoconcepción como peregrino o buscador. Deberíamos esperar aquí solo una modesta rata de progreso. El mismo Johnson identificó como factores que predisponen a un abierto trabajo inter-(pero en sus términos multi-) disciplinario efectivo: el ser 'suficientemente libre del chauvinismo disciplinar' y 'filosóficamente flexible' (Giri 1998). Estos factores no son ni auto-nutrientes ni no-nutribles. Johnson los deja como exógenos: algunos los tienen, otros no, por tanto hay que escoger los del primer tipo para ciertos trabajos. Necesitamos hacer mucho más que eso, sobre todo en la economía que es la propia disciplina de Johnson.

Además de entender las fuerzas del hábito y de los intereses creados, una sicología de la economía debería reconocer y movilizar los motivos de solución de enigmas y los ideales sociales de la mayoría de los economistas. El atractivo de la Economía se ha sustentado en la promesa de combinar los goces de una ciencia del tipo de la física -pues la mercantilización de las sociedades modernas proporciona un universo para las mediciones y los cálculos- con las satisfacciones de la relevancia social. El destacar probables contradicciones en la economía, que incluyen tanto problemas internos como contradicciones con otros hallazgos, puede tener alguna influencia; por ejemplo, el mostrar que la economía dominante tiene una ideología de pluralismo de valores y sin embargo ha ignorado ciertos tipos de sistemas de valores. Se puede examinar las fuerzas del interés propio en la economía misma, señalando como los economistas pueden a menudo escoger suposiciones que son las más convenientes para producir artículos y estatus y evitar disputas con sus financiadores, y concentrarse en manipular datos de dudosa calidad. De manera similar, la ampliación de los medios usados y conocidos por los economistas-añadiendo entrevistas, entrevistas de grupo, testimonios, ejercicios de participación, encuestas de valoración contingente, e involucramiento en proyectos IDa menudo proporciona evidencia incompatible con sus suposiciones disciplinares originales y contribuye a replantear sus ideas. ${ }^{6}$

Norgaard (1994) aporta este desafío. La delimitación del rango de los agentes económicos solamente a los individuos, las empresas y el gobierno, se basa en la noción de las personas como autónomas, asociales, ni formadas por una cultura o un grupo ni participando en la formación de culturas y grupos, que incluyen las familias y las comunidades en diversos niveles. Sin embargo son estos grupos los que mejor se adaptan a los presupuestos de la economía: la habilidad para explorar y conocer su entorno y asumir todos los costos y beneficios de sus acciones. Ellos son ignorados pues si la economía los tomase en serio perdería su determinismo -ya que el comportamiento humano es visto como emergiendo de las interacciones discursivas tanto en esos niveles de agencia como entre ellos por la vía de la modificación cultural- y los economistas perderían su papel econocrático de sumos sacerdotes.

\footnotetext{
${ }^{6}$ Necesitamos más estudios sociológicos y sicológicos, mas auto análisis, de los economistas y de la disciplina de la economía. Nótese, por ejemplo, los hallazgos confirmados de Frank et al. (1993) acerca de que en América los estudiantes de economía a la vez comienzan siendo y se vuelven más egoístas que otros estudiantes; y el trabajo de Colander (1987), Klamer (1989) y McCloskey (1998).
} 
Söderbaum (2000) considera que 'poco se puede esperar en términos de pluralismo de los departamentos de economía tal como están ahora'. Hay demasiados intereses creados, demasiada renta por cobrar en la posición casi monopólica de la economía dominante. Otros lugares, como las escuelas de estudios empresariales, ofrecen a menudo mejores opciones para un nuevo pensamiento. Podría ser más fructífero apoyar procesos de cambio en centros de poder como el Banco Mundial que concentrarse en los departamentos de economía de las universidades. Las agencias de políticas parecen más orientadas hacia la realidad y más aptas para responder bajo presión por los fracasos de sus prescripciones, como en el África SubSahariana y en la Rusia post-comunista, y a crisis inesperadas como las del Asia Oriental en 1997 y el colapso financiero global de 2008. Por otra parte, señala Wallerstein (1996), no es sabio abandonar las disciplinas tradicionales a los de mente estrecha.

\section{Un ecosistema complejo de investigadores}

A partir de nuestro examen tanto de la disciplinariedad como de la inter-disciplinariedad, propondré una imagen similar de varias maneras a la de Johnson, reconociendo diferentes tipos de trabajo validos más algunas restricciones viables en la ID. Pero me baso más en la crítica a la disciplinariedad y voy así más allá de él, para buscar también una reestructuración a largo paso de las ideas.

Siempre necesitaremos una comunicación regular entre una diversidad de tipos y estilos de trabajo. En la vida intelectual como en otras esferas, necesitamos "capital social conectivo" que se extienda entre las comunidades así como también 'capital social cohesivo' que sirva de unión dentro de ellas. Esta conexión y comunicación conllevan una variedad de redes y papeles y algunos lenguajes compartidos.

Por redes me refiero a los vínculos de organización y entre organizaciones y lugares de reunión, así como a sus miembros y el contacto informal.

(1) Por redes se hace referencia a los vínculos organizacionales e inter organizacionales y a los lugares de encuentro, así como también a sus miembros y al contacto informal. Necesitamos trabajo ID en distintos centros, tales como los de estudios del desarrollo, pero también como un factor de catalización entre las disciplinas Klein (1996), muestra muchos ejemplos). Desde los centros ID algunos miembros deberían mantener vínculos con sus 'propias' disciplinas, mientras que desde centros disciplinares algunos miembros deberían ligarse al trabajo interdisciplinar.
(2) El trabajo inter-disciplinar no puede florecer simplemente por la interacción entre especialistas disciplinares. Dos tipos de roles que algunas veces son objeto de disputa pero que revisten considerable importancia son: los metodólogos y, no menos importantes para el trabajo orientado a la acción, los intermediarios generalistas (Easton 1991). Quienes hacen el necesario papel de tender puentes conceptuales y elaborar síntesis pueden estar basados en una disciplina (por ejemplo, en el caso de la interacción entre economía y sicología, Scitovsky en la economía y Lea en la sicología), o, de modo inusual, ser verdaderos maestros en más de una disciplina, (por ejemplo Sen en la interacción entre economía y ética), o ser intermediarios híbridos.

(3) A pesar de que 'puentes' y "capital social conectivo" son metáforas útiles, de muchas maneras una imagen superior es la de un ecosistema, dentro del cual muchas especies e híbridos coexisten e interactúan (y algunas veces se comen a otros y otras veces son comidos): una pluralidad de actividades de investigación inter relacionadas y las correspondientes comunidades, como lo insinúan los mapas que tomamos y extendimos de Johnson y Wallerstein y en aquellos proporcionados por Klein (1996), Szostak (2003) y otros. Un ecosistema complejo requiere un sistema complejo de conceptos y modelos para describirlo y entenderlo. La observación continua del trabajo científico puede llevarnos más allá del uso casual de metáforas (ver por ejemplo, Mansilla (2010). En la Sección 5 trataremos de ser más precisos acerca de los tipos de interdisciplinariedad.

(4) La interacción requiere marcos intelectuales mutuamente accesibles y aceptables. A menudo un marco superior no es suficientemente accesible y aceptable para otros cuya cooperación se necesita. El impresionante trabajo de Scitovsky (1976) para extraer de la sicología una base más fundamentada empíricamente para el consumidor y la teoría del bienestar aparentemente exigía demasiado ajuste por parte de los economistas. Tuvo impacto no en la economía sino en un nuevo enclave entre disciplinas, la sicología económica. La teoría de la exclusión social posiblemente incluye mejor análisis social que la teoría del capital social o la teoría de las capacidades pero está más allá de la capacidad de absorción de la mayoría de los economistas. Teorías inferiores pueden a veces servir mejor como puentes. En la Sección 6 nos preguntaremos que tan lejos programas de investigación particulares podrían llevar a la economía al mundo social.

\section{UN MAPEO MAS COMPLETO: DEFINICION DE LA VARIANTES EN LA ID.}

'Interdisciplinariedad' puede ser una etiqueta problemática. 
Primero, se ha convertido en un término odiado por los que se oponen a la educación de cafetería. Segundo, 'inter' connota entre, pero no todos los usos respetan esto. Estos dos problemas podrían ser trascendidos, sin embargo, y esto es lo tercero, aun si se respeta la connotación, muchas formas y resultados de las relaciones entre disciplinas son posibles (Frodeman et al. 2010). El operar solo con un nivel o con un conjunto indiferenciado de niveles a menudo trae inconsistencias o reduccionismo, la ecuación de ID con solo una variante. Precisamos un conjunto más claro y completo de términos (Tabla 3).

Tabla 3: Relaciones entre disciplinas.

\begin{tabular}{|c|c|c|}
\hline & NO AMISTOSAS & AMISTOSAS \\
\hline \multirow{3}{*}{ SIN RELACIÓN } & Ignorancia del otro o de los otros & \\
\hline & Autarquía planeada & Bienquerencia distante \\
\hline & Ridiculización mutua del otro o los otros a & Intercambio (= parte de \\
\hline \multirow[t]{3}{*}{ RELACIÓN LIMITADA } & Antagonismo e ignorancia en asociaciones & Asociación amistosa: \\
\hline & no felices. & Actividades multi-disciplinarias \\
\hline & $\begin{array}{l}\text { Mercantilismo (= búsqueda de la } \\
\text { exportación y no de la importación) }\end{array}$ & compartidas \\
\hline \multirow{3}{*}{ RELACIÓN INTENSA } & Competencia & Matrimonio, y producción de una prole \\
\hline & & hibrida \\
\hline & Conquista & Fusión \\
\hline
\end{tabular}

Todas estas relaciones ocurren a menudo. Klein (1996) registra términos correspondientes en la literatura como 'zonas de intercambio', 'lenguajes pidgin' y 'lenguajes creole'. Las relaciones de alguna manera son reflejo de aquellas entre naciones. Así como la mayoría de los libros de historia de las naciones resaltan sus victorias y pasan más rápidamente por sus derrotas, las disciplinas tienden a restar importancia a sus propias fallas.

¿Cuáles de las relaciones se adaptan a la etiqueta ID? De acuerdo con los diccionarios Webster y Collins el adjetivo interdisciplinario significa 'que están involucradas dos o más disciplinas'. Las Universidades involucran muchas disciplinas, de acuerdo con esta definición entonces ellas son ID, aun si las disciplinas se ignoran una a la otra excepto cuando se encuentran en comités de gestión. El diccionario de Oxford es más útil: interdisciplinario significa 'de o entre más de una rama del conocimiento'. Esto coincide con el prefijo 'inter-', que significa 'entre (por ejemplo intercontinental); o de manera mutual o recíproca (cruzamiento) y sugiere intercambio; ver también (Karlqvist 1999). Además, tenemos ya un término mejor, multidisciplinario, para describir relaciones constructivas que implican solo contribuciones separadas son interacción.

El sustantivo interdisciplinariedad podría de manera similar usarse de varios modos para significar: 1 . el estado real de las relaciones entre disciplinas, aun si lo que se tiene es ignorancia mutual o lucha; $\mathrm{y}$, de modo más relevante y restringido, 2. relaciones constructivas entre disciplinas, incluida una complementariedad no constructiva; 3. relaciones activas entre disciplinas, aun si son de antagonismo; y más restrictivamente, 4. relaciones cooperativas en las que cada disciplina aprende de las otras, para mejorarse a sí mismas o para hacer juntas nuevas cosas, e incluso construir nuevos campos. Los casos 1 y 2 estarían cubiertos por la definición del Webster, y mucho del uso Americano incluye una variante débil del caso 2: cualquier combinación de cursos, o de académicos, de más de una disciplina. Los programas de Estudios Interdisciplinares en las universidades americanas permiten a los estudiantes combinar diversos temas en lugar de llenar los prerrequisitos para un estudio especializado ulterior como lo prefieren muchos académicos. 'Entre las disciplinas' no hace referencia en estos casos ni al contenido de las componentes ni a la interacción entre ellas-las disciplinas pueden no relacionarse entre sí y puede que se deje a los estudiantes hacer las conexiones- sino más bien a su combinación y a la localización de los programas fuera del control de los departamentos disciplinares: entre ellos por así decirlo. Ello puede significar aislamiento y no interacción entre las disciplinas. Un uso derogatorio de la etiqueta ID parece provenir de esa imagen de 'escogencia de cafetería' norteamericana de programas de estudio. En un uso más adecuado, ID se refiere a los casos 3 y 4 , interacción o coordinación. Así Leeson \& Minogue (1988), escribiendo acerca de la creación de una Maestría en Estudios del Desarrollo en la Universidad de Manchester, registró que la meta era 'crear a partir de las muchas ofertas diferentes un curso genuinamente interdisciplinario y no contentarse con una mera adición de un menú fascinante pero 
meta era 'crear a partir de las muchas ofertas diferentes un curso genuinamente interdisciplinario y no contentarse con una mera adición de un menú fascinante pero descoordinado'.

Extendamos y modifiquemos el conjunto de etiquetas presentado en el tan citado reporte OECD (Apostel et al., 1972). ${ }^{1}$ Podemos distinguir las siguientes variantes $y$ sucesores o asociados de las interdisciplinariedad.

1. Multi-disciplinariedad. Si bien 'multi' implica solo la presencia de más de una disciplina, cuando se contrasta con 'inter-', sugiere que están involucradas disciplinas complementarias pero no interactuantes, como sucede en un proyecto agrícola o en uno de construcción, o en algunas publicaciones de estudios de área, donde cada disciplina hace su aporte por separado, presentado a menudo en un capítulo independiente con su propio autor. Esto puede llamarse también pluridisciplinariedad. ${ }^{2}$ Conlleva una adición no crítica de diferentes monodisciplinas. No significa sin embargo que los miembros de las disciplinas vayan a ser menos imperiales en su estilo.

Debemos distinguir estos casos multidisciplinares no interactuantes de todas las variantes que se presentan más adelante, donde existe interacción entre disciplinas y que por tanto se adaptan mejor a la etiqueta ID. La mayoría del trabajo que se autodenomina ID en los estudios del desarrollo ha sido de hecho MD (Minogue 1988). A pesar de que algunas revistas de estudios del desarrollo publican muchos artículos interdisciplinarios-como Development and Change or Progress in Development Studies-muchas otras simplemente toman artículos de un rango de disciplinas, tales como World Development y Journal of International Development. Una prueba interesante sería: ¿leen aquellos de los que publican en World Development y no son economistas muchos o alguno de los artículos en economía allí publicados, y viceversa?

2. Disciplinariedad abierta. Aquí las disciplinas interactúan y buscan aprender unas de otras, especialmente en el análisis de un tópico compartido. Berge \& Powell (1997) usan otro termino pero captan aquello a lo que me refiero: 'los investigadores identifican y confrontan diferencias en perspectivas y enfoques; no para ser "mejor" [juzgados] ...sino para que cada uno aprenda de los otros y les contribuya; y por tanto para hacerse más consciente de sus propios méritos y limitaciones'. Nieuwenhuijze (1978) a

\footnotetext{
1 Apostel et al. (1972) contrastaron 'multi-', 'inter-', 'pluri-' (la yuxtaposición de disciplinas relacionadas) y la 'trans-' disciplinariedad.

${ }^{2}$ Los prefijos pluri- y poli- difieren solo en su procedencia: el primero del latín, y el segundo del griego.
}

menudo adopta este uso: 'Al defender nuestro alegato por la interdisciplinariedad ...de hecho no abogamos más que por el intento sistemático por producir segundos pensamientos, quizás una mala conciencia, en aquella persona que confía en que su propia disciplina es todo lo que necesita para ser un estudioso del desarrollo... [para hacerle] caer en cuenta de la necesidad de mirar por encima de la cerca, para ver que están tratando de hacer los colegas en otras disciplinas' Nieuwenhuijze (1978).

3. La apertura y el intercambio interdisciplinarios pueden conducir a:

(a) Campos interdisciplinarios, en el sentido descrito antes, tales como la administración pública, la planeación regional, y los estudios del desarrollo. Un campo ID puede involucrar todas las formas bajo los aquí presentados \#1-3, y aún más, puesto que trabaja en la encrucijada de varias disciplinas y conjuntos de demanda prácticas. Un campo tal nunca puede, y de hecho nunca debería, integrarse bajo una simple definición aceptada.

(b) Nuevos campos sub-disciplinares, en los que una disciplina aborda con los métodos existentes problemas que se perciben de manera nueva aprendiendo de otras disciplinas; un ejemplo de esto es la economía ambiental.

(c) Híbridos: aquí surgen nuevos campos con nuevos métodos y también con nuevos problemas, y con participación entre disciplinas. La economía ecológica por ejemplo no es solo economía como la tratan los ecologistas, o los economistas que han leído algo de ecología, sino por aquellos que ha absorbido una perspectiva ecológica. Esto conlleva un re-pensamiento real y no simplemente la extensión a un nuevo tema de un enfoque existente. Insiste en vínculos ubicuos y fundamentales, en la complejidad y por lo tanto en una perspectiva más amplia. La economía ambiental ha tenido mucho más dinero y poder detrás de ella (Brasso en Ravaioli 1995), y en contraste se aferra de manera típica al enfoque de alta abstracción de la economía dominante, que trata el mundo como desconectado, de modo que todas las otras variables se tratan como fijas. Esto puede facilitar la elaboración de predicciones simplistas, seguidas a menudo por una racha de recomendaciones políticas.

La (Tabla 4) identifica otros más de esos campos híbridos y nuevas sub-disciplinas. Extiende la clasificación de intercepciones de métodos y temas de McNeill (1999), al incluir también la tercera componente de la Triada de Wallerstein, la ciencia política, y su cantera tradicional, la política. 
4. (a) Se tiene Disciplinariedad imperial cuando una disciplina existente trata de absorber o desplazar a otra. Aquí el ecosistema incluye depredadores que quieren eliminar a otros, o al menos colonizarlos. '..."imperialismo económico" es probablemente una buena descripción de lo que yo hago' dijo Gary Becker (Swedberg 1991). Su colega cercano George Stigler marcha bajo la misma bandera (Stigler 1984). El socio de ambos James Coleman espera más bien absorber la economía en la sociología, pero a través de una reforma de la sociología por medio de la importación desde la economía de conceptos de la elección racional de la economía y su puesta en un papel central (Swedberg 1991).

(b) Mega-disciplinariedad: aquí se aspira a una disciplina de ciencia social bien integrada y para todos los usos; como una ciencia social de elección racional, algo de Marxismo, y socio-biología. Trascendería las disciplinas existentes pero no la disciplinariedad. La mega-disciplinariedad podría ser aún más peligrosa que la disciplinariedad si aumenta la arrogancia respecto a las pretensiones del conocimiento y elimina las perspectivas contrarias.

5. (a) Super-disciplinariedad. 'Super' denota más arriba, más allá, o por sobre. Aquí se ofrece una teoría que pretende abarcar, localizar y delimitar un número de disciplinas en competencia, indicando cómo ellas encajan en diferentes contextos: como quizás por ejemplo en un Marxismo más refinado o en la Teoría Cultural (TC) de Mary. ${ }^{3}$ Sus defensores a menudo continúan hacia a un mega-modo, buscando no solamente vincular sino englobar.

(b) Supra-disciplinariedad. 'Supra' denota también más arriba, más allá; pero con la adición de trascendiendo. Aquí un marco pretende localizar y delimitar enfoques en competencia y guiar entonces la selección relativa a contextos y propósitos. Roe (1998) busca sobrepasar la súper-oferta de TC, definiendo una variedad de tipos de teorización entre las cuales se mueve de acuerdo con propósitos lo mismo que contextos, con TC solo como uno de esos tipos. (Deberíamos notar que TC y Roe tratan con enfoques, no solo con disciplinas).

\section{Trans-disciplinariedad: Para el Centro Internacional para la}

\footnotetext{
3 'La Teoría Cultural' sostiene que podemos convenientemente entender la gama de puntos de vista sobre casi cualquier tópico de la organización social en términos de cuatro perspectivas que son contendientes permanentes, y cuyas debilidades en cada caso refuerzan las otras perspectivas. Un punto de vista en existencia es 'jerárquico', y refleja la aceptación de altas lealtades de grupo y una alta regulación del comportamiento individual (alto dominio de grupo-alto en ligaduras); el segundo es 'individualista' (bajo dominio de grupo-bajo en ligaduras); el tercero es 'igualitario' (alto dominio de grupo-bajo en ligaduras); el cuarto es 'fatalista' (bajo dominio de grupo-bajo en ligaduras).
}

Investigación Transdisciplinaria (CIRET) en Paris, un enfoque trans-disciplinario va a través de las disciplinas, las une, y va más allá de ellas (website CIRET). Esto respeta de manera adecuada el sentido original de trans-: a través, al otro lado de, más allá. ${ }^{4}$ Su enfoque utiliza la teoría de la complejidad y la lógica difusa para entender e interconectar múltiples niveles de realidad (Max-Neef 2005). La transdisciplinariedad es necesaria porque 'no existen problemas "económicos", "sociales", "sicológicos", sino solo problemas, que no respetan las fronteras disciplinares (Myrdal 1975). El propósito en conectar campos y trascender barreras, no elaborar un súper formalismo unificado, ver Klein 2004). ${ }^{5}$

Se puede también hablar de meta-disciplinariedad: 'meta-' denota después, más allá, con una sugerencia de cambio de tipo. Aquí, como en el análisis de sistemas y en algunos análisis de políticas, y en varios campos del diseño, buscamos un marco para ciertos problemas de casos y propósitos específicos, no un marco disciplinar estándar ni aun un conjunto amplio de ellos para escoger, ver por ejemplo: Stretton (1969), Rein \& Schön (1994). Todas las disciplinas relevantes son utilizadas como herramientas, y a ninguna se le concede un estatus independiente; ellas son más bien puntos de partida, que son entonces dejados de lado en el proceso de tratar con casos reales, como se hace también en la buena historiografía, la buena biografía, los buenos estudios de caso. Esta postura ha sido también ampliamente conocida como 'trans-disciplinariedad', ver el estudio de Wickson et al. (2006) y difiere del uso del CIRET. ${ }^{6}$

Nuestro análisis da algo así como una docena de variantes, mostradas en la (Tabla 5). Ellas se pueden agrupar en menos casos principales, que se muestran en la columna a mano derecha. El número de casos principales que necesitamos distinguir es, sugiero, significativamente mayor que el trío convencional (multi-, inter-, trans-) que todavía es reproducido por Klein (2010). Podemos referirnos a las formas 2 a 6, y a combinaciones de ellas, como ID. Mediante este uso, la multidisciplinariedad no es automáticamente ID. Sin embargo, algunas personas usan el término ID de

\footnotetext{
4 El reporte de OECD de 1972 (Apostel et al. 1972) en contraste usó 'trans-disciplinariedad' para significar mega-disciplinariedad: subsunción de más de una disciplina en un conjunto común de principios. No parece continuarse con este uso en trabajos más recientes, ver Wickson et al. (2006), para un estudio).

Thompson (2004) analiza mucho del trabajo actual en transdisciplinariedad, incluso en la investigación en educación.

6 Difiere también de una tradición en lengua alemana en la que 'transdisciplinariedad' se iguala con una focalización en la investigación en problemas sociales prácticos (Hadorn et al. 2008, 2010). Existen ya nombres mejores que 'transdisciplinariedad' para este tipo de trabajo (tales como 'ciencias de políticas', 'ciencias de diseño, etc.).
} 
manera más flexible para cubrir también ese caso (\#1); y algunas otras lo usan de manera más restringida, solo para los casos 2, 3 y 5 .

¿Por qué clasificar dada la inevitable imperfección e incompletitud de cualquier lista? Porque hay confusión remediable tanto entre autores como en ellos mismos, aun en algunos de los mejores. Wallerstein (1996). oscilan entre los términos 'multi-disciplinariedad' e 'interdisciplinariedad', y no ofrecen una terminología clara. Lo mismo se aplica para Easton (1991), Dogan \& Pahre (1990), Nieuwenhuijze (1978) y Johnson (1986), entre otros. Johnson (1986) por ejemplo declara: 'Hay personas que se autodenominan interdisciplinarias, implicando que pueden servir como fuente de muchas diferentes clases de excelencia disciplinar. En general, los interdisciplinarios fracasan en ofrecer excelencia fuerte en todas las disciplinas que pretenden representar'. Pero pocos interdisciplinarios pretenden la poli-disciplinariedad, que es la maestría de más de una disciplina. Y no lo necesitan pues el criterio es más bien una comprensión adecuada de para las exigencias de un trabajo particular (Klein 1996). ${ }^{7}$ Muchos de ellos afirman ser ID en el sentido de la apertura, la voluntad y la capacidad para interactuar, comunicar y aprender. De hecho en otra parte Johnson mismo aboga por esto, pero habiendo convertido 'ID' en una etiqueta peyorativa carece de un término para describir lo que defiende:

No se está afirmando aquí que los economistas deberían ser multi-disciplinarios [maestros de otras disciplinas; sentido que él le da a ID]. Lo que está implicado más bien es que los economistas involucrados en la solución práctica de problemas y en la investigación de tópicos específicos deberían estar preparados para aceptar la guía de las filosofías y los diferentes puntos de vista metodológicos $\mathrm{y}$ las técnicas asociadas con las disciplinas a las cuales contribuyen los economistas (Johnson 1986).

En otras palabras deberían ser interdisciplinarios en el sentido de buscar aprender de los demás.

\footnotetext{
${ }^{7}$ Klein (1996) advierte que el bilingüismo es entonces una falsa metáfora para ID: 'Los pidgin y los creole son las formas típicas de la comunicación interdisciplinar'. Así, la investigación doctoral interdisciplinaria, más allá de la dificultad de su mayor escala y complejidad, no debería enfrentar la barrera adicional del sometimiento a un estilo MD de examen por una batería de especialistas disciplinares. Sus criterios a menudo son inapropiados al exigir una elaboración y precisión máximas de lo que son solo sub-aspectos de un estudio ID, frente a una profundidad suficiente en términos de la investigación global. De manera alterna, las tesis mono-disciplinares deberían estar expuestas a la mirada crítica de otras disciplinas. Muchas de ellas serán altamente vulnerables.
}

\section{‘CAPITAL SOCIAL CONECTIVO' - INVOLUCRANDO LA ECONOMÍA EN LA CIENCIA SOCIAL}

\section{Las pasaderas preceden a las habilidades del oficio en la interdisciplinariedad}

La trans- y la meta-disciplinariedad plantean exigencias más altas. Albert Hirschman introdujo conceptos de la ciencia política y de la sociología en la economía, y viceversa, no con base en un manifiesto radical como el de 'El enfoque económico' de Becker, sino por medio de la experimentación sutil. El determinar cuáles importaciones conceptuales ayudan en cuáles casos constituye un trabajo de artesanía altamente calificado. Requiere un amplio repertorio de conceptos y métodos, y la capacidad de seleccionar, aplicar y evaluar. 'No hay una llave maestra, un camino principal para integrar las ciencias sociales; es un asunto esencialmente de invención caso por caso. Esto no es satisfactoria para mis colegas o para las personas más jóvenes' (Hirschman, en Swedberg 1991). Krugman (1993) arguye que Hirschman en consecuencia no fundó ninguna escuela, ningún programa de investigación; que tiene admiradores pero no discípulos.

Más ampliamente manejables quizás sean marcos de trabajo ID identificables que vinculen o trasciendan los modelos disciplinares; por ejemplo, Hirschman creó el marco de trabajo salida/voz/lealtad. Tales marcos de trabajo pueden ayudar a llenar algunas de las funciones asignadas a una disciplina: proveer enfoques, lenguaje y seguridad compartidos; estructurar el entrenamiento; moldear el discurso público. A partir de tal base y entrenamiento pueden surgir algunos maestros del oficio. Sin pasaderas intermedias el salto desde la disciplinariedad puede ser muy grande. Y para aquellos que no pueden ser maestros del oficio, se han dado pasos valiosos hacia la disciplinariedad transversal y abierta. Usualmente necesitamos 'un tipo de frontera cognitiva (Star \& Griesemer 1989) que facilite la comunicación a través de diferentes culturas' (Jasanoff \& Wynne 1998). Dado el poder y la insularidad de mucho de la economía, precisamos en particular marcos de trabajo que pueden fructíferamente vincular economistas y otros científicos sociales (y ambientales). Algunos de los marcos pueden ser inferiores como ciencia social a las alternativas disponibles, pero superiores por su función. Mencionemos brevemente algunos pocos candidatos. El propósito es ilustrar este tema general, no pasar juicos drásticos sobre contendientes particulares.

El avance imperial de la teoría de la 'elección pública' y de una interpretación bastante estrecha de la 'elección racional' en la ciencia política, la administración y la sociología en la pasada generación, ha sido popular entre muchos científicos 
sociales con orientación formal. Estos modelos son útiles si se los trata como tipos ideales que dan primeras aproximaciones en algunas situaciones o simplemente como líneas de base para ver que tanto las situaciones divergen del modelo (ver, por ejemplo, Dunleavy (1991) y el trabajado de Robert Bates y Jon Elster). Si se convierten en puentes con un flujo en una sola vía, y se tratan como interpretaciones precisas de casi todas las situaciones, se vuelven desastrosos, una versión degenerada de ID (ver Stretton \& Orchard (1994)). Son enfoques altamente riesgosos, fácilmente mal usados.

La Nueva Economía Institucional (NEI) es menos imperial, debido a que sus raíces están en la teoría organizacional y en el derecho, y no solo en la economía de los costos de transacción (Oliver Williamson en Swedberg (1991)). A pesar de que todavía se corre el riesgo de reificación de los tipos ideales, comparada con la teoría de la elección racional, la NEI funciona más fácilmente como una arena para el aprendizaje en dos o más vías. No obstante sigue siendo limitada y limitante en su base y suposiciones informacionales (Harriss et al. 1995), como se ve en el enfoque a la gestión de recursos de propiedad comunes (Mosse 1997). Para Kurien (1996), la NEI muestra la futilidad de tratar de injertar en una base económica neoclásica aspectos substantivos seleccionados todavía con preferencia a la conveniencia analítica sobre el realismo.

En este contexto, la aparición de una nueva estrella en el firmamento (del Banco Mundial) -'el capital social' - ha tenido mayor significación potencial, arguyen comentadores cuyos puntos de vista merecen atención. Avergonzado por su debilidad en la creación de programas sostenibles, algunos economistas del Banco Mundial y asociados buscaron un factor explicativo que añadir al trio de los tradicionales bienes de capital, capital humano y capital ambiental. Impacientes con las varias interpretaciones del 'capital social' en otros estudios sociales, algunos pensaron que todas ellas se podrían fusionar (Serageldin \& Grootaert 2000) y luego someterse a medición.

Tabla 4. Una extensión del mapa de McNeill de disciplinas de base y transversales.

\begin{tabular}{|c|c|c|c|c|}
\hline \multirow[t]{2}{*}{$\begin{array}{c}\text { ESTUDIADA } \\
\text { POR LA: }\end{array}$} & \multicolumn{4}{|c|}{ ESTUDIO DE LA: } \\
\hline & NATURALEZA & ECONOMÍA & SOCIEDAD & POLÍTICA \\
\hline ECOLOGÍA & Disciplina base & Economía ecológica & $\begin{array}{l}\text { ¿Ecología humana? } \\
\text { ¿Socio-biología? }\end{array}$ & ¿Socio-biología? \\
\hline ECONOMÍA & $\begin{array}{l}\text { Economía } \\
\text { ambiental }\end{array}$ & Disciplina base & $\begin{array}{c}\text { 'Elección racional'; } \\
\text { nueva economía } \\
\text { institucional; (algo de) } \\
\text { teoría del capital social }\end{array}$ & $\begin{array}{c}\text { 'Elección pública'; } \\
\text { 'nueva economía } \\
\text { política' }\end{array}$ \\
\hline $\begin{array}{c}\text { SOCIOLOGÍA/ } \\
\text { ANTROPO-LOGÍA. }\end{array}$ & $\begin{array}{c}\text { Antropología } \\
\text { ecológica }\end{array}$ & $\begin{array}{l}\text { Econ. antropo., } \\
\text { econ. sociología }\end{array}$ & Disciplina base & Sociología política \\
\hline CIENCIA POLÍTICA & Ecología política & $\begin{array}{c}\text { Algo de 'economía } \\
\text { política' }\end{array}$ & $\begin{array}{c}\text { Teoría social centrada } \\
\text { en el poder }\end{array}$ & Disciplina base \\
\hline
\end{tabular}

A pesar de sus limitaciones, la noción de 'capital social' probablemente trajo más del mundo real a los mundos mentales del Banco y de la economía dominante. La incorporación de un pequeño de antropólogos al Banco Mundial desde los finales de la década de 1980, con la ayuda de los argumentos de Kottak (1991) acerca de que cuanto más participativos los proyectos mayores los retornos económicos, tuvieron valiosos efectos en algunas áreas del diseño de programas. Sin embargo a mediados de la década de 1990, el Banco todavía empleaba 28 economistas por cada otro científico social (Edwards 1999). Pocos de los miembros del staff del Banco Mundial continuarían escuchando al oír un ataque al 'Homo economicus', pero muchos más aceptarán una discusión del 'capital social', señaló uno de los economistas que llevaban a cabo tal discusión ${ }^{8}$ El antropólogo Steve Rayner señaló que, para muchos economistas, el 'capital social' es una manera de hablar acerca de lo social sin tener que considerar a profundidad a la sociedad. En las palabras de Norman Uphoff, 'el capital social' podría ser el caballo de Troya para traer a nálisis

\footnotetext{
${ }^{8}$ Esta y las dos siguientes anotaciones fueron hechas o reportadas en la conferencia Solstrand de Mayo 2000 sobre Capital Social, en la Universidad de Bergen.
} 
social' podría ser el caballo de Troya para traer análisis social al desarrollo económico. Descontentos con la inelegancia el concepto, los economistas ganadores del Premios Nobel Arrow y Solow en (Dasgupta \& Serageldin 2000) vieron solo la pobreza para ajustarse a las nociones tradicionales de 'capital' y pasaron por alto este papel ID.

Muchas de las esperanzas sobre medidas confiables, agregación, generalizaciones de alcance mundial, modelos transferibles, proyectos de promoción manejables probablemente no se han cumplido, al menos cuando son evaluadas por otros. El concepto mismo podría incluso desaparecer más tarde. La pregunta clave es si los economistas se retirarán a la disciplinariedad o habrá un impacto a más largo plazo y más profundo, después de la entrada de un staff extra no economista y nuevas variables en el análisis, que con el tiempo exigirán y legitimarán nuevas posturas metodológicas para los economistas.

El discurso del 'capital social', que se encuentra en muchos otros círculos diferentes al del Banco Mundial, podría estar funcionando como un punto de encuentro ID y un vehículo para traer a la economía un pensamiento con más consciencia histórica, menos universalista, más humilde (Thompson 2000). Esto sería suficientemente inusual como para que el foro no fuera descartado a la ligera.

\section{¿Marcos utilizables o mega-pretensiones?}

Fine (2001, 2010) ha hecho críticas poderosamente argumentadas al capital social. Se podría estar de acuerdo con la mayoría de los puntos de Fine sobre el contenido de las ideas del 'capital social', y notar sin embargo que la perspectiva de sociología del conocimiento que él usa: analizar cómo tales ideas podrían encajar con las necesidades actuales del capitalismo mundial, es reduccionista. Él pierde de vista el potencial desafiante del concepto, como un puente o una escala en una evolución del pensamiento. Una alternativa implícita en el fondo de su crítica es un Marxismo sofisticado. Las grandes virtudes del Marxismo han surgido de su determinación por hacer conexiones a través de las divisiones convencionales del pensamiento, para ver los significados sociales y sicológicos de un bien o mercancía; para resaltar los vínculos entre el poder económico y la política, que no se tienen en cuenta en la ciencia social disciplinar (incluso en mucho de la teoría de la elección pública) como el poder frecuente del dinero para comprar la policía, el poder judicial, el legislativo y a los que gobiernan; y mucho más. El declive del Marxismo refleja los fracasos, intelectuales y prácticos, de las versiones mega y súperdisciplinares. Sirve más como una fuente de preguntas que como un conjunto de marcos y modelos fijos y torpes. ${ }^{1}$

Tomemos otro ejemplo, la 'teoría cultural' creada en las décadas de 1960 y 1970 por la antropóloga Mary Douglas. Ha sido elaborada y aplicada por otros, de manera notable por sus estudiantes y compañeros de trabajo Steve Rayner y Michael Thompson y por los prominentes científicos políticos Aaron Wildavsky and Christopher Hood (Thompson et al. 1990, Hood 1998, Verweij et al. 2007). Figura con fuerza por ejemplo en los cuatro volúmenes del proyecto en enfoques de las ciencias sociales sobre el cambio climático de la Fundación Batelle (Rayner \& Malone 1998), que atrajo a un gran número de científicos sociales y ambientales de una amplia gama de disciplinas. La 'Teoría Cultural' intenta proporcionar una síntesis súper-disciplinar de muchos asuntos, pero su carácter simplificador y sus pretensiones de gran teoría podrían algunas veces ser una barrera para la interacción interdisciplinaria Podría llegar a ser percibida como un culto con un conjunto de respuestas demasiado inmediatas, en vez de un foro donde analistas de varios orígenes pueden encontrar ayuda para continuar con sus preguntas, sobre todo hablando unos con otros. La promoción de la ID por medio de una teoría que tiene fuertes pretensiones y es propuesta principalmente por una escuela en una disciplina sería menos efectiva que la propagación desde un marco de trabajo común. Más promisorio es el tratamiento flexible de Hood que usa el enfoque como un 'generador de variedades' para forjar ideas y opciones.

El marco de trabajo de análisis de derechos diseñado por Amartya Sen de manera similar parece animar la disciplinariedad abierta ya que proporciona un puente (Sen 1981, Dreze \& Sen 1989). Ha llamado la atención y ha sido relativamente fructífero a través de un número de disciplinas y en la discusión interdisciplinaria (Gasper 1993). En el trabajo de 'derechos ambientales' de Leach et al. (1997), por ejemplo, un grupo de EID en Sussex proveniente de la antropología, la geografía humana y la agricultura, que trabajaba con colaboradores de Ghana, India y Sur África, reportó que encontró el análisis de derecho útil al forzarlos a considerar de modo sistemático un rango total de conexiones a las que ellos de otra forma probablemente no habrían prestado atención. Y esto a pesar de algunas oscuridades internas, y malentendidos acerca de las categorías de Sen por parte de muchos usuarios, y aun su contenido quizás bastante limitado de análisis social. Sen es de hecho un economista de mente abierta pero mucho más

\footnotetext{
1 Jessop \& Sum (2001) abogan de modo plausible por 'una economía política cultural', que 'incluya seriamente el giro argumentativo, narrativo, retorico y lingüístico en el análisis de la economía política, y examine así 'la construcción cultural y social [y la reconstrucción] de fronteras entre lo económico y lo político’ y de agentes y sus modos de cálculo.
} 
Ambiente y Sostenibilidad 2012 (2): 3-28

Revista del Doctorado Interinstitucional en Ciencias Ambientales

Figura 5: Algunas formas de disciplinariedad e inter-disciplinariedad.

\begin{tabular}{|c|c|c|}
\hline VARIANTE & EXPLICACIÓN & $\begin{array}{l}\text { CLASIFICACIÓN } \\
\text { CONDENSADA }\end{array}$ \\
\hline 0. Disciplinas cerradas & Modelo de islas & Pura disciplinariedad (D) \\
\hline 1.Multi-disciplinariedad & Presencia de más de una disciplina & \\
\hline 1a. Pluri-disciplinariedad & Uso de más de una disciplina: complementarias, aditivas pero no influyendo una sobre otra. & $\begin{array}{l}\text { Multi-disciplinariedad } \\
\text { MD }\end{array}$ \\
\hline 1b. Poli-disciplinariedad & Maestría por parte de un individuo de más de una disciplina & \\
\hline 2a. Disciplinariedad abierta & $\begin{array}{l}\text { Algunas disciplinas hacen intercambios y aprenden unas de otras; también cooperan y comparten } \\
\text { tópicos y tareas. Sin que necesariamente se formalizan nuevos sub-campos o campos cruzados o } \\
\text { campos interdisciplinares. }\end{array}$ & $\begin{array}{l}\text { Disciplinariedad abierta } \\
\text { DA }\end{array}$ \\
\hline 2b. Formato vinculante & El intercambio se facilita por un formato para movilizar y relacionar una variedad de insumos & \\
\hline 3a. Campo ID & $\begin{array}{l}\text { Un campo practico orientado hacia problemas recurre a varias disciplinas y puede elaborar sus } \\
\text { propias adiciones; permanece vagamente integrado (por ejemplo la administración pública) }\end{array}$ & Campo ID \\
\hline 3b. Sub-disciplinariedad & $\begin{array}{l}\text { Una disciplina se expande para tratar con un nuevo campo, por ejemplo, uno que estaba } \\
\text { previamente en otra disciplina, sin cambio en sus conceptos ni métodos }\end{array}$ & $\begin{array}{l}\text { Sub-disciplinariedad } \\
\text { (Cruzamiento disciplinar } \\
\text { A) }\end{array}$ \\
\hline 3c. Hibridación & $\begin{array}{l}\text { Un nuevo campo especializado integrado emerge como un hibrido a partir de la interacción de } \\
\text { problemas, conceptos, métodos y teorías en la intersección de más de una (sub) disciplina }\end{array}$ & $\begin{array}{l}\text { Hibridación } \\
\text { (Cruzamiento disciplinar } \\
\text { B) }\end{array}$ \\
\hline $\begin{array}{l}\text { 4a. Disciplinariedad } \\
\quad \text { imperial }\end{array}$ & Una disciplina busca desplazar otras disciplinas & \\
\hline $\begin{array}{l}\text { 4b. Mega- } \\
\text { disciplinariedad }\end{array}$ & La meta de una sola ciencia social integrada, sea por absorcion imperial, fusion o alguna otra ruta & Mega-disciplinariedad \\
\hline $\begin{array}{l}\text { 5a. Super- } \\
\text { disciplinariedad }\end{array}$ & $\begin{array}{l}\text { Una teoría cuyo propósito es mostrar cual disciplina encaja con cual contexto; y una práctica que } \\
\text { recurre a cualesquiera disciplinas ('alimentos pre-cocinados') que ayuden en un dado caso }\end{array}$ & \\
\hline $\begin{array}{l}\text { 5b. Supra- } \\
\text { disciplinariedad }\end{array}$ & Una teoría cuyo propósito es mostrar cual disciplina encaja con cual propósito y contexto & Supra-disciplinariedad \\
\hline $\begin{array}{c}\text { 6a.. Trans- } \\
\text { disciplinariedad }\end{array}$ & Entender, conectar y transcender las disciplinas & Trans-disciplinariedad \\
\hline $\begin{array}{c}\text { 6b. Meta- } \\
\text { disciplinariedad }\end{array}$ & $\begin{array}{l}\text { Uno no procede escogiendo entre 'alimentos pre-cocinados' o combinando trozos de ellos: más bien } \\
\text { uno selecciona variables y herramientas de manera más flexible, de acuerdo con la situación } \\
\text { estudiada, usando técnicas del oficio post-disciplinares. }\end{array}$ & \\
\hline
\end{tabular}


otras ciencias sociales (ver su entrevista en Swedberg (1991)), Gasper (2000b). Sin embargo el análisis de derechos se ha mostrado adecuado para ayudar a economistas, geógrafos y otros a plantear preguntas relevantes que los llevan más allá de sus marcos heredados. No abre solamente una conversación entre economistas, sino una ventana para mirar más allá. Deberíamos aceptar la inevitabilidad de muchas líneas y estilos de conversación; y, mientras situamos su trabajo, alabar a cada uno de los que genera una conversación interdisciplinar sostenida. El enfoque de capacidades de Sen, adoptado por Sen's Mahbub ul Haq como base para el trabajo de Desarrollo Humano de la ONU, ha funcionado de modo similar. Dirigiendo con fuerza la atención a otros determinantes de la calidad de vida además de los bienes, ha contribuido a ampliar la economía del desarrollo y a aumentar la cooperación interdisciplinar (Gasper 2000b, 2008).

El análisis de derechos y el de capacidades son ejemplos de formatos flexibles que sin embargo proporcionan una ayuda considerable para identificar los factores que se deben tener en cuenta. Igualmente importantes para el trabajo ID, al ayudar a evitar exclusiones a priori de factores y tópicos, son los formatos para evaluar y construir argumentos de políticas, ver ejemplos en Dunn (2007), Gasper (1996). Estos pueden proveer tanto espacio como indicaciones específicos para traer a colación tópicos. Pueden ayudarnos a hacernos preguntas en el ejemplo que vimos antes, acerca de los impactos comparativos de la educación privada en la construcción de nación, sobre la fuga de cerebros y la voluntad de trabajar en sectores prioritarios y no solo sobre las ganancias de los graduados. Cuanto menos anticipatoria y más exploratoria sea la formulación de un problema, mas trans-disciplinario será el análisis, ver ejemplo en Brewer (1999).

\section{CONCLUSIÓN}

Los estudios del desarrollo se han basado en forma considerable en la defensa de la interdisciplinariedad para justificar su espacio organizacional distintivo. Sin embargo han quedado absorbidos a menudo en la rutina y han puesto poca atención a la teoría y a los aspectos prácticos de la ID. Se ve ampliamente que se confunde la ID, la interacción entre disciplinas, con el dominio de múltiples disciplinas, o con la mera adición de contribuciones disciplinares sin una influencia mutual substancial, o se la identifica con una variedad extrema como la megadisciplinariedad.
Este estudio ha destacado y tratado de responder la necesidad de conceptos más precisos, de una imagen pluralista de relaciones válidas, de una visión no utópica de la ID, y de medidas prácticas para el progreso a corto y largo plazo. Debemos distinguir múltiples modos y propósitos del análisis social, y emplear una ecología más compleja de las ciencias sociales. Esto incluye tener claridad sobre los papeles y las raíces así como también los límites de la disciplinariedad, y ser conscientes de la variedad de tipos de multi e inter-disciplinariedad. Necesitamos en particular fortalecer interacciones colegiadas enriquecedoras y efectivas entre economistas y (otros) científicos sociales y ambientales. Las medidas prácticas incluyen la promoción de "capital conectivo", en forma marcada formatos intelectuales que sean atractivos a través de más de un grupo, para contrarrestar el "capital vinculante" entre disciplinas.

Al corto plazo, como lo han sugerido Johnson y Perkins, el análisis inter-disciplinario de situaciones y la cooperación en casos relacionados con políticas son a menudo más factibles y algunas veces más importantes que la construcción interdisciplinaria de teoría. Sería de ayuda también el reconocimiento de los papeles de intermediación y de enlace, incluso cuando se toman decisiones en perfiles y selección para un empleo. En el largo plazo, la educación multi y en especial inter-disciplinaria es probablemente vital para una mayor ID en la investigación y para suavizar los lazos monógamos de compromiso e identidad. Foster-Carter sugiere que títulos conjuntos, o al menos conjuntos secundarios de cursos (minors) muy sustanciales, deberían ser la norma en ciencias sociales. Además de proveer recursos intelectuales, aumentan la disposición y el sentido de legitimidad para un posterior trabajo en ID.

Tanto para el corto como para el largo plazo, necesitamos marcos de trabajo que abran y faciliten la conversación interdisciplinaria y ofrezcan actividades concretas atractivas. El enfoque de "ángel vengador" a la ID-'Rechazando la ignorancia y los grotescamente crudos supuestos de mi querido colega sobre el tópico $X^{\prime}$ - puede ser menos efectivo que el enfoque 'Consiguiendo el Sí: buscando conjuntamente generar nuevas actividades y percepciones que trasciendan y beneficien todos los diferentes puntos de partida intelectuales. La urgencia de los temas del ambiente $y$ el desarrollo constituye una oportunidad enorme para esto, y al involucrar científicos naturales y muchos otros, tal trabajo mantiene la división frecuente entre economistas y otros científicos sociales favorablemente en perspectiva. 


\section{REFERENCIAS}

ANDERSON, P. ARROW, K. J. \& PINES, D. (eds). 1988. The Economy as an Evolving Complex System. Addison-Wesley, Redwood City. 336 pp.

APOSTEL, L. BERGER, G. BRIGGS, A. \& MICHAUD, G. (eds). 1972. Interdisciplinarity: Problems of Teaching and Research in Universities. OECD (CERI - Centre for Educational Research and Innovation), Paris. 321 pp.

APTHORE, R. 1996. Reading Development Policy and Policy Analysis. European Journal of Development Research 8(1): 16-35.

BAKER, W. 1998. Bridging the Philosophical Divide Between Sociology and Economics. Econsoc Editorial, on Worldwide Web.

BECKER, E. \& JAHN, T. (eds). 1999. Sustainability and the Social Sciences. Zed Books, London. 336 pp.

BECKER, G. 1976. The Economic Approach to Human Behavior. In The Economic Approach to Human Behavior, 314. University of Chicago Press, Chicago. 320 pp.

BEDI, A. S. \& GARG, A. 2000. The Effectiveness of Private versus Public Schools: The Case of Indonesia. Journal of Development Economics 61 (2): 463-494.

BERGE, G. \& POWELL, N. 1997. Reflections on Inter disciplinary Resarch: A Synthesis of Experiences from Research in Development and Environment. Centre for Development and the Environment, University of Oslo. Working Paper 4.

MANSILLA, V. 2010. Learning to Synthesise: the development of interdisciplinary understanding. En: FRODEMAN, R. THOMPSON, K. J. MITCHAN, C. (eds). The Oxford handbook of interdisciplinarity: 288-306. Oxford University Press, UK.

BOTTOMORE, T. 1971. Sociology. 2nd edition. London: George Allen and Unwin.

BREWER, G. 1999. The challenges of interdisciplinarity. Policy Sciences 32: 327-337.

BREWER, G. (ed). 1999. The Theory and Practice of Interdisciplinary Work. Special issue of Policy Sciences: 32(4). $121 \mathrm{pp}$.
CALHOUN, C. \& RHOTEN, D. 2010. Integrating the Social Sciences: theoretical knowledge, methodological tools, and practical applications. En: FRODEMAN, R. THOMPSON, K. J. MITCHAN, C. (eds). The Oxford handbook of interdisciplinarity: 103-118. Oxford University Press, UK.

COLANDER, D. \& KLAMER, A. 1987. The Making of an Economist. Journal of Economic Perspectives 1: 95-112.

DASGUPTA, P. \& SERAGELDIN. I. (eds). 2000. Social Capital - a multi-faceted perspective. The World Bank, Washington, DC. 424 pp.

DOGAN, M. 2000. The moving frontier of the social sciences. En: QUAH, S. \& SALES, A. (eds). The International Handbook of Sociology: 35-49. Sage Publications, London.

DOGAN, M. \& PAHRE, R. 1990. Creative Marginality: Innovations at the intersections of social sciences. Westview Press, Boulder (CO). 278 pp.

DREZE, J. \& SEN, A. 1989. Hunger and Public Action. Oxford: Clarendon. 398 pp.

DUNLEAVY, P. 1991. Democracy, Bureaucracy and Public Choice: Economic Explanations in Political Science. The Economic Journal 102: 990-992.

DUNN, W. N. 2007. Public Policy Analysis (4th edition). Prentice Hall, Upper Saddle River, NJ. 528 pp.

EARL, P. 1983. The Economic Imagination. Brighton: Whatsheaf.

EASTON, D. 1991. The Division, Integration, and Transfer of Knowledge. En: EASTON, D. \& SCHELLING, C. (eds), Divided Knowledge: Across Disciplines, Across Cultures: 736. Sage Publications. Newbury Park, CA.

EDWARDS, M. 1999. Future Positive: International Cooperation in the $21^{\text {st }}$ Century. Earthscan, London. 304 pp.

FINE, B. 1999. A Question of Economics: is it colonising the social sciences?. Economy and Society 28(3): 403-25.

FINE, B. 2001. Social Capital versus Social Theory: Political Economy and Social Science at the Turn of the Millennium. Routledge, London: 293 pp.

FINE, B. 2010. Theories of Social Capital: Researchers Behaving Badly. Pluto Press, UK. 288 pp.

FLOTTUM, K. DAHL, T. \& KINN, T. 2006. Academic Voices. 
John Benjamins, Amsterdam. 309 pp.

FOSTER-CARTER, A. 1998. Against divisions among the social sciences. Times Higher Education Supplement, 9 October.

FRANK, R. H. GILOVICH, T. \& REGAN, D.T. 1993. Does Studying Economics Inhibit Cooperation?. Journal of Economic Perspectives 7(2): 159-71.

FRODEMAN, R. KLEIN, J. T. \& MITCHAM, C. (eds). 2010. The Oxford Handbook of Interdisciplinarity. Oxford University Press, New York. 580 pp.

GASPER, D. 1990. Education for Regional Planning. En: Helmsing, A. \& Wekwete, K. (eds). Subnational Plannign in Southern and Eastern Africa: 261-303. Ashgate Publishing, Avebury.

GASPER, D. 1993. Entitlements Analysis: Relating Concepts and Contexts. Devolpment and Change 24(4): 425-466.

GASPER, D. 1996. Analysing Policy Arguments. European Journal of Development Research 8 81): 36-62.

GASPER, D. 2000a. Strengthening 'Public and Development' in the New South Africa. En: THERON, F. \& SCWELLA, E. (eds). The State of Public and Development Management in South Africa: 165-188. University of Stellenbosch, Sudafrica.

GASPER, D. 2000b. Development as Freedom: Taking Economics Beyond Commodities - The Cautious Boldness of Amartya Sen. Journal of International Development 12(7): 989-1001.

GASPER, D. 2008. From 'Hume's Law' To Policy Analysis for Human Development. Review of Political Economy 20(2): 233-256.

GERSTEIN, D. DUNCAN, L. SMELSER, N. L. \& SPERLICH, $S$ (eds). 1988. The Behavioral and Social Sciences: Achievements and Opportunities. National Academy Press, Washington, DC. 282 pp.

GIRI, A. K. 1998. Transcending Disciplinary Boundaries. Critique of Anthropology 18: 379- 404.

GIRI, A. K. 2002. The Calling of a Creative Transdisciplinarity. Futures 34(1): 103-105.

HANSSON, B. 1999. Interdisciplinarity: For what purpose?. Policy Sciences, 32(4): 339-43.
HAYEK, F. A. 1956. The Dilemma of Specialization. En: WHITE, L. (ed). The State of the Social Sciences: 462-73. Chicago University Press. Chicago.

HARRISS, J. HUNTER, J. \& LEWIS, C. (eds). 1995. The New Institutional Economics and Third World Development. Routledge, London. 376 pp.

HETTNE, B. 1990. Development Theory and the Three Worlds. (first edition). Longman Pub Group. 296 pp.

HETTNE, B. 1995. Development Theory and the Three Worlds. (Second edition). Longman Pub Group. 336 pp.

HADORN, H. HOFFMANN-RIEM, H. BIBER-KLEMM, S. GROSSENBACHER-MANSUY, W. JOYE, D. POHL, C. WIESMANN, U \& ZEMP, E. (eds). 2008. Handbook of Transdisciplinary Research. Dordrecht: Springer. 448 pp.

HADORN, G. POHL, C. \& BAMMER, G. 2010. Solving problems through transdisciplinary research. En: FRODEMAN, R. THOMPSON, K. J. MITCHAN, C. (eds). The Oxford handbook of interdisciplinarity: 431-452. Oxford University Press, UK.

HOOD, C. 1998. The Art of the State: Culture, Rhetoric and Public Management. Oxford University Press, New York. 261 pp.

JASANOFF, S. 2010. A field of its own: The emergence of science and technology studies. En: FRODEMAN, KLEIN, J. T. \& MITCHAM, C. (eds): 191-205. Oxford University Press, Oxford.

JASANOFF, S. \& WYNNE, B. 1998. Science and Decisionmaking. En: RAYNER \& MALONE (eds). The Social Framework: 1-87.

JESSOP, B. \& SUM, N-L. 2001. Pre-disciplinary and Postdisciplinary Perspectives. New Political Economy 6(1): 89-101.

JOHNSON, G. L. 1986. Research Methodology for Economist - Philosophy and Practice. Macmillan, NewYork. 288 pp.

JOHNSON, G. L. \& ZERBY, L. 1973. What Economist Do About Values. University o Michigan. 255 pp.

KARLQVIST, A. 1999. Going beyond disciplines - The meanings of interdisciplinarity. Policy Sciences 32: 379-83.

KLAMER, A. \& MCCLOSKEY, D. 1989. The Rhetoric of Disagreement. Rethinking Marxism 2(3): 140-161. 
Ambiente y Sostenibilidad 2012 (2): 3-28

Revista del Doctorado Interinstitucional en Ciencias Ambientales

ISSN: 2339-3122

KLEIN, J. T. 1996. Crossing Boundaries: Knowledge, Disciplinarities and Interdisciplinarities. University of Virginia Press, Charlottesville. 281 pp.

KLEIN, J. T. 2004. Prospects for Transdisciplinarity. Futures 36(4): 515-526.

KLEIN, J. T. THOMPSON, J. 2010. A Taxonomy of Interdisciplinarity. En: FRODEMAN, R. THOMPSON, K. J. \& MITCHAN, C. (eds). The Oxford handbook of interdisciplinarity: 15-30. Oxford University Press, UK

KOTTAK, C. P. 1991. When People Don't Come First: Some sociological lessons from completed projects. En: CERNEA, M. (ed). Putting People First: 431-464. Oxford University Press, New York.

KRUGMAN, P. 1993. The Fall and Rise of Development Economics. En: RODWIN, L \& SCHON, D. (eds).

Rethinkings the Development Experience - essays in honor of Albert O. Hirschman. Brookings, New York.

KUHN, T. S. 1970. The Structure of Scientific Revolutions. (2nd edition). University of Chicago Press, Chicago. 210 pp.

KURIEN, C. T. 1996. Rethinking Economics: Reflections Based on a Study of the Indian Economy. Sage Publications, New Delhi. 272 pp.

LAKOFF, G. \& JOHNSON, M. 2003. Metaphors We Live By. 2nd edition. University of Chicago Press Chicago. 256 pp.

LEACH, M. MEARNS, R. \& SCOONES, I. 1997. Community Based Sustainable Development. Consensus or Conflict?. IDS Bulletin 28(4) special issue.

LEESON, P. \& MINOGUE, M. 1988. Perspectives on Development - Cross-disciplinary themes in development studies. Manchester University Press, Manchester. 257 pp.

LIPSEY, R. G. 2001. Successes and failures in the transformation of economics. Journal of Economic Methodology 8(2): 169-201.

LIPTON, M. 1970. Interdisciplinary Studies in Less Developed Countries. Journal of Development Studies 7(1): 5-18.

MARTINEZ-ALIER, J. 1999. The Socio-ecological Embeddedness of Economic Activity: The Emergence of a Transdisciplinary Field. En: BECKER, E. \& JAHN, T. (eds). Sustainability and the social sciences: a cross-disciplinary approach to integrating environmental considerations inte theoretical reorientation: 112-140. Zed Books, London and New York.

MAX-NEEF, M. 2005. Foundations of Transdisciplinarity. Ecological Economics 53: 5-16.

MCCLOSKEY, D. 1998. The Rhetoric of Economics. 2nd edition. University of Wisconsin Press, Madison WI. 248 pp.

MCNEILL, D. 1999. On Interdisciplinary Research: with particular reference to the field of environment and development. Higher Education Quarterly 53(4): 312-332.

MILLER, C. A. 2010. Policy challenges and university reform. En: FRODEMAN, KLEIN, J. T. \& MITCHAM, C. (eds): 333344. Oxford University Press, Oxford.

MINOGUE, M. 1988. Problems of theory and practice in development studies. En: LEESON \& MINOGUE (eds). 244250 .

MOSSE, D. 1997. The Ideology and Politics of Community Participation. GRILLO, I. R. \& STIRRAT, R. (eds). Disurses of Development, Oxford Berg.

MYRDAL, G. 1975. Against the Stream: Critical Essays on Economics. Random House, New York. 336 pp.

NIEUWENHUIJZE, C. A. O. VAN. 1978. The Study of Development and the Alleged Need for an Interdisciplinary Approach. Occasional Paper 67, Institute of Social Studies, The Hague.

NORBYE, O. 1992. Book review. Forum for Development Studies, Oslo, 1992 (1).

NORGAARD, R. 1994. Development Betrayed - the end of progress and a coevolutionary revisioning of the future. Routledge, London. 296 pp.

OECD, 1982. The University and the Community. Paris: OECD.

RAVAIOLI, C. 1995. Economist and the Environment - What the top economist say about the environment. Zed Books, London. 192 pp.

RAVETZ, J. R. 1973. Scientific Knowledge and its Social Problems. Transaction Publishers, Harmondsworth UK. 449 pp.

RAYNER, S. \& MALONE, E. (eds). 1998. Human Choice and Climate Change. Battelle Press, Columbus, OH. 1728 pp. 
REIN, M. \& SCHÖN, D. 1994. Frame Reflection. Basic Books, New York. 247 pp.

ROE, E. 1998. Taking Complexity Seriously. Springer, Boston. $152 \mathrm{pp}$.

ROE, E. 1999. Except Africa: Remarking Development, Rethinking Power. Transaction Publishers. New Brunswick, NJ. 204 pp.

ROTBLATT, S. 1998. Tug of war for knowledge. Times Higher Eduction Supplement. 7 December.

RUTGERS, M. 1998. Paradigm lost: crisis as identity of the study of public administration. International Review of Administrative Sciences 64: 553-564.

SALTER, L. \& HEARN, A. 1996. Outside the Lines: Issues in Interdisciplinary Research. McGill-Queen's University Press, Montreal. 212 pp.

SCHOENBERGER, E. 2001. Interdisciplinarity and social power. Progress in Human Geography 25(3): 365-82.

SCITOVSKY, T. 1976. The Joyless Economy. Oxford University Press, New York. 352 pp.

SEN, A. 1981. Poverty and Famines: An Essay on Entillement and Deprivation. Oxford University Press, Clarendon. 257 pp.

SERAGELDIN, I. \& GROOTAERT, C. 2000. Defining Social Capital. An Integrating View. En: DASGUPTA \& SERAGELDIN (eds). 40-48.

SIGMA XI, 1988. Removing the Boundaries: Perspectives on Cross-disciplinary Research. New Haven: Sigma Xi.

SÖDERBAUM, P. 2000. Ecological Economics. A political economics approach to environment and development. Earthscan, London. 224 pp.

STAR, S. \& GRIESEMER, J. 1989. Institutional ecology, "translations" and boundary objects. Social Studies of Science 19:387-420.

STIGLER, G. J. 1984. Economics - the imperial discipline. Scandinavian Journal of Economics 86: 310-313.

STOKOLS, D. HALL, K. L. MOSER, R. P. FENG, A. MISRA, S. \& TAYLOR, B. K. 2010. Cross-disciplinary team science initiatives. En: FRODEMAN, R. THOMPSON, K. J. \& MITCHAN, C. (eds). The Oxford handbook of interdisciplinarity: 471-493. Oxford University Press, UK.

STRETTON, H. 1969. The Political Sciences. Routledge \& Kegan Paul.

STRETTON, H. \& ORCHARD, L. 1994. Public Goods, Public Enterprise and Public Choice - Theoretical Foundations of the Contemporary Attack on Government. Macmillan, London. $312 \mathrm{pp}$.

SWEDBERG, R. 1991. Economics and Sociology - redefining their boundaries. Oxford University Press, New Delhi. 361 pp.

SZOSTAK, R. 2003. A schema for unifying human science: interdisciplinary perspectives on culture. Susquehanna University Press. Selinsgrove, PA. 389 pp.

THOMPSON, G. 2000. Between Markets and Hierarchies. Oxford University Press, Oxford. 272 pp.

THOMPSON, M. ELLIS, R. \& WILDAVSKY, A. 1990. Cultural Theory. Westview, Boulder CO. 251 pp.

UVIN, P. 1999. Development Aid and Structural Violence: The case of Rwanda. Development 42(3): 49-56.

VERWEIJ, M. \& THOMPSON, M. (eds), 2007. Clumsy Solutions for a Complex World. Palgrave Macmillan, Basingstoke UK. 272 pp.

WALDROP, M. M. 1993. Complexity: The emerging science at the edge of order and Chaos. Viking, London. 384 pp.

WALLERSTEIN, I. (ed). 1996. Open The Social Sciences Report of the Gulbenkian Commission on the Restructuring of the Social Sciences. Standford University Press, Stanford, CA. 124 pp.

WICKSON, F. A. CAREW \& A. RUSSELL, 2006. Transdisciplinary research: characteristics, quandaries and quality. Futures 38(9): 1046-1059.

WOODWARD, S. 1995. Balkan Tragedy: Chaos and Dissolution after the Cold War. Brooking, Washington D. C. $536 \mathrm{pp}$. 